\title{
New sunspots and aurorae in the historical Chinese text corpus? Comments on uncritical digital search applications
}

\author{
D.L. Neuhäuser ${ }^{1}$, R. Neuhäuser ${ }^{2}{ }^{\star}$, J. Chapman $^{3,4}$ \\ ${ }^{1}$ Schillbachstrasse 42, 07745 Jena, Germany \\ ${ }^{2}$ Astrophysikalisches Institut, Universität Jena, Schillergässchen 2-3, 07745 Jena, Germany \\ ${ }^{3}$ Department of History, University of Oklahoma-Norman, 455 West Lindsey Street, Room 403A, Norman, Oklahoma \\ 73019-2004, United States \\ ${ }^{4}$ Department of History, University of California-Merced, COB2, 5200 North Lake Road, Merced, CA 95343, United \\ States
}

Received July 2017, accepted Oct 2017

Published online

Key words historical Chinese observations - aurorae - sunspots - solar activity - history of astronomy

\begin{abstract}
We review some applications of the method of electronic searching for historical observations of sunspots and aurorae in the Chinese text corpus by Hayakawa et al. (2015, 2016, 2017ab), Kawamura et al. (2016), and Tamazawa et al. (2017). However, we show strong shortcomings in the digital search technique as applied by them: almost all likely true sunspot and aurora records were presented before (e.g. Xu et al. 2000), which is not mentioned in those papers; the remaining records are dubious and often refer to other phenomena, neither spots nor aurorae (this also applies to Hayakawa et al. 2017c). The alleged aurorae in Hayakawa et al. (2015) and Kawamura et al. (2016) show a broad peak around full moon, not expected for aurorae. Hayakawa et al. (2017a) use the Korean report At night, the gate of heaven was opened (between AD 992 Dec 26 and 993 Jan 25, i.e. close to the ${ }^{14} \mathrm{C}$ variation AD 993/4) to estimate the Dst index of solar activity, even though the text does not fulfil any discriminative aurora criteria (except night-time). Most of the above publications include very few Chinese texts and translations, and their tables with abbreviated keywords do not allow the reader to consider alternative interpretations (the tables also do not specify which records mention night-time). We have compared some of their event tables with previously published catalogues and found various discrepancies. There are also intrinsic inconsistencies, misleading information (lunar phase for day-time events), and dating errors. We present Chinese texts and translations for some of their presumable new aurorae: only one can be considered a likely true aurora (AD 604 Jan); some others were selected on the sole basis of the use of the word light or rainbow. Several alleged new aurorae present observations beside the Sun during day-time. There are well-known comets among their presumable aurorae. We also discuss, (i) whether heiqi ri pang can stand for black spot(s) on one side of or beside the sun, (ii) aurora color confusion in Hayakawa et al. $(2015,2016)$, and (iii) whether white and unusual rainbows can be aurorae.
\end{abstract}

(c) 2018 WILEY-VCH Verlag GmbH \& Co. KGaA, Weinheim

\section{Introduction}

Solar activity of the past centuries and millennia can be reconstructed with radioisotopes, sunspots, and aurorae. Historical observations of these phenomena recently attracted new interest because of the expectation that strong ${ }^{14} \mathrm{C}$ variations as published for AD 775 and 994 (Miyake et al. 2012, 2013) may be related to large sunspots and strong aurorae if these were due to super-strong solar flares. Usoskin et al. (2013) and Zhou et al. (2014) searched for aurorae around AD 775. Stephenson (2015) searched for general astronomical evidence around AD 774/5 and concluded: Were the years around $A D 774 / 5$... indeed unusual for the frequency of aurorae ... ? ... both East Asian and European records suggest that the answer seem to be in the negative ... [T] here is little sign for unusual solar activity. The lack of strong aurorae (and sunspot sightings) between AD 774 to 786 led Chapman et al. (2015) and Neuhäuser \& Neuhäuser (2015a)

\footnotetext{
^ E-mail: rne@astro.uni-jena.de
}

to cast doubt on the flare hypothesis, so that Neuhäuser \& Neuhäuser (2015c) suggested instead that solar activity dropped markedly for a few years. This suggestion is consistent with weak solar wind and, hence, strong cosmic ray influx and radioisotope production on Earth.

Many catalogues of historical aurorae have been compiled, e.g. Matsushita (1956), Keimatsu (1970, 1971, 1972, 1973, 1974, 1975, 1976), Yau et al. (1995), Xu et al. (2000), Lee et al. (2004), and Chapman et al. (2015) for East Asian records and de Mairan (1733), Schöning (1760), Jeremiah (1870), Fritz (1873), Vyssotsky (1949), Link (1962), Rethly \& Berkes (1963), Newton (1972), and Stothers (1979) for European records, as well as Rada \& al-Najeh (1997), Cook (2001), and Basurah $(2005,2006)$ for West Asian reports; Schove (1955, 1964, 1984), Dall'Olmo (1979), Krivsky \& Pejml (1988), Silverman (1998), Hetherington (1996), Usoskin et al. (2013), Stephenson (2015) and Neuhäuser \& Neuhäuser (2015a) compiled catalogues for several cultures (partly for short time intervals). 
Naked-eye sunspots records were compiled mainly by Keimatsu (1970, 1971, 1972, 1973, 1974, 1975, 1976), Clarke \& Stephenson (1978), Wittmann \& Xu (1987), Yau \& Stephenson (1988), Xu et al. (2000), Vaquero et al. (2002), Lee et al. (2004), and Vaquero (2007).

All these catalogues were compiled by individually checking candidates across multiple primary sources.

Recently, Hayakawa et al. (2015, henceforth H+15) used the electronic database Scripta Sinica of the Academia Sinica, Taiwan, to search electronically for certain words or combinations of words referring to aurorae and sunspots in the Chinese Song dynasty chronicle for the period AD 960-1279. Within only the Astronomic Treatise in the Song Shi (History of the Song Dynasty), they searched for aurora and sunspot records, while others have previously searched for aurorae and sunspots also in other documents covering the same period, inside and outside the Song Shi. Then, Hayakawa et al. (2016, henceforth $\mathrm{H}+16$ ) extended their search for more wordings, e.g. considering white rainbows (bai ni) as aurorae.

In this paper, we show shortcomings in the blind electronic search technique as employed by $\mathrm{H}+15, \mathrm{H}+16$, and Kawamura et al. (2016, henceforth $\mathrm{K}+16)$ as well as in Tamazawa et al. (2017) and Hayakawa et al. (2017a, 2017b).

We stress that some previous other aurora catalogues are also not free of misidentifications (other phenomena), as studied in detail for the decades around AD 775 by Chapman et al. (2015) and Neuhäuser \& Neuhäuser (2015ab), e.g.:

(a) Silverman (1998) has 49 entries from $\mathrm{AD}$ 731 to 825 in his online aurora catalogue (now at spdf.sci.gsfc.nasa.gov), but some events are listed several times, and some of them are likely non-auroral: there are 17 different likely true aurorae remaining in Silverman's catalogue from $\mathrm{AD} 731$ to 825 , according to the criteria in Neuhäuser \& Neuhäuser (2015a).

(b) Usoskin et al. (2013) listed 14 to 16 different events as aurorae from $\mathrm{AD} 765$ to 786 , but some phenomena listed are halos or otherwise doubtful, e.g. the European events listed for $\mathrm{AD} 773$ (two young men on white horses), 774 (red cross), and 776 (two inflamed shields). These were all halo phenomena (Neuhäuser \& Neuhäuser 2015ab). Of the 14 to 16 events listed, nine are likely true or potential aurorae (Neuhäuser \& Neuhäuser 2015a).

(c) The global Chronicle of pre-telescopic astronomy by Hetherington (1996) includes for example the red cross of AD 776 three times, namely in AD 773, 774, and 776, twice with wrong reference; in fact, it was most likely a halo display in AD 776 (Newton 1972, Neuhäuser \& Neuhäuser 2015ab).

The often referenced aurora catalogues by Fritz (1873) and Link (1962), who partly revised Fritz (1873), likewise include non-auroral events such as halo displays (e.g. Neuhäuser \& Neuhäuser 2015ab).

After discussing the criteria in the automatic searches discussed (e.g., Hayakawa et al. 2015, H+15) in Sect. 2.1, we consider whether their electronic search technique can be considered complete (Sect. 2.2). In Sect. 3, we discuss publications by Hayakawa et al. (2015, H+15), Kawamura et al. (2016), and Tamazawa et al. (2017) on various dynasties. In Sect. 4, we discuss certain terminology issues of Chinese aurora and sunspot records, namely ri pang as in Hayakawa et al. (2017b) (Sect. 4.1), aurora color as in Hayakawa et al. (2015, 2016) (Sect. 4.2), and rainbows as in Hayakawa et al. (2016) (Sect. 4.3). We present final remarks in our conclusion (Sect. 5).

\section{Digital searches for aurorae and sunspots}

Hayakawa et al. $(2015, \mathrm{H}+15)$ searched for aurorae and sunspots only in the Tianwen zhi (Treatise on Celestial Patterns, or more loosely, Treatise on Astronomy) in the Song Shi. We will now discuss various aspects of the search technique. Our considerations also apply to Hayakawa et al. (2016, 2017a, 2017b), Kawamura et al. (2016), and Tamazawa et al. (2017).

\subsection{Selection criteria}

$\mathrm{H}+15$ searched for descriptions that could be regarded as records of sunspots or auroras ... such as black spot and red vapor (their section search method). $\mathrm{H}+15$ add that sunspots are described as black spots or black vapors in the sun or in terms such as "the sun was weak and without light" (their section on sunspot records). According to their table 1 on sunspots, they also included a report on the crescent-like shape (of the sun) as a report on sunspot(s) (AD 1005 Feb 6). In their section on auroral records, they add that they surveyed the words that refer to luminous phenomena, such as vapor, light, and cloud, excluding those without dates and those observed explicitly during the day $(\mathrm{H}+15) ; \mathrm{H}+15$ also flag red sunsets and red sunrises as aurorae (their table 2). $\mathrm{K}+16$ mention that they searched for vapor (qi), cloud (yun), and light (guang) as aurorae (and for black spot (heizi) and black vapors (heiqi) for sunspots, but found none), and that they excluded those associated with the Sun or Moon, and those explicitly observed at daytime (their section 2.1).

It would be best, if the authors would give a clear and full list of all words and combinations they have searched for. If some texts, including certain wordings which could have been regarded as the relevant phenomenon, are not interpreted as that particular phenomenon, one should then compile a list of false positives (i.e. other events) with clear reasoning as to why they are dubious. Reports on light or cloud could have been anything including meteors, bolides, halo displays, comets, rainbows, fogbows, novae, supernovae, or other meteorological events.

Chapman et al. (2015) discussed the Chinese wording for aurorae and other celestial phenomena in more detail: "Any study of aurorae in medieval China is complicated by the fact that there was no discrete concept of aurorae 
as such in medieval Chinese astronomy. Scholars have variously identified observations of flowing stars (liu xing) or stars that fall (xing yun), various sorts of halos (huan), and $q i$ as aurorae. Flowing stars and stars that fall in almost every case should be identified with meteors or bolides, while huan (rings) are most likely lunar or solar halo displays; flowing stars in some instances may also refer to comets. The most likely instances of aurorae in Chinese historical records are identified as $q i$, yet not all or even most observations of $q i$ were indeed aurorae. While $q i$ is variously translated as ether(s) or vapour(s), material objects, including clouds, planets, stars, comets, and meteors, were thought to be constituted of $q i$ in Chinese cosmology. Because $q i$ was thought to emanate from the Earth itself, often in response to developments in the politico-religious sphere of the imperial court, explanations for aberrant astronomical and meteorological phenomena were grounded in politics.... In terms of practical observation of celestial patterns (i.e. tianwen, a term often imprecisely translated as astronomy or astrology), clouds (yun) and $q i$ were included in a single category (yunqi), and recorded in the same section of the astronomical treatises."

Pre-modern scholars in Europe and Arabia also considered all transient celestial phenomena like comets and (super-)novae (as well as aurorae) as happening in the Earth's atmosphere, following Aristotle's Meteorology.

Furthermore, the meaning of words changes with time (usually, they get more specific). E.g., the words cometes in Latin and nayzak in Arabic is mostly translated to comet; before about AD 1600, it did not only mean comet in today's sense, but had a more general meaning of apparently extended transient celestial phenomenon including novae and supernovae (Goldstein 1965, Stephenson \& Green 2002, Neuhäuser et al. 2016), comparable to guest star (kexing) in the Chinese. We will discuss another example below (rainbow, see Sect. 4.3).

In Neuhäuser \& Neuhäuser (2015a), criteria are suggested which indicate likely true aurora borealis; such characteristics are indeed needed given the heterogeneous phenomena and reports:

(1) Sky brightness: Night-time, whereas day-time excludes an auroral interpretation; sightings at twilight do not fulfill the night-time criterion, but have to be investigated in more detail (sometimes, night-time is indicated indirectly, e.g. by mentioning stars or constellations). The lunar phase should also be considered (aurorae are less likely to be noticed if the sky is too bright).

(2) Direction: aurorae borealis, as their Latin name implies, are normally in the northern region; wordings like rays to/from the zenith, east to west, and west to east are also well possible. While aurorae borealis can also partly be seen to the south, if the observer is located north of the aurora oval, a southern direction usually contradicts an auroral interpretation; sightings in the south do not fulfil the direction criterion.

(3) Color: phenomena with reddish, fiery, blood(y), scarlet, purple, crimson, and similar color can be auroral, sometimes reported together with green, blue, yellow, or violet, while blue, yellow, violet, or black/dark alone without reddish would be dubious, because one should expect the mention of some red in addition to other colors; green aurorae are seen only far north; reports on other phenomena (e.g. white, bright, brilliant, glow, light) have to be investigated in more detail (but do not fulfil an aurora criterion).

(4) Dynamics like pulses, changes, motion, etc.: the words fiery and fight can indicate dynamics; the word fire seems to indicate dynamics only in (heterogeneous) European reports, while fire in (more homogeneous) East Asian reports only indicates a reddish color; to discriminate them from other variable phenomena like halo displays, a careful analysis of text and context is needed.

(5) Repetition: aurorae may occur in the following nights, but not for longer than a few days.

See Neuhäuser \& Neuhäuser (2015a) for more details.

The aim of such criteria is mainly to differentiate the categorization of a report from other possible celestial events. Even if several criteria are fulfilled, one still has to check whether the whole report is more likely pointing to an aurora rather than some other phenomenon: e.g. a report like white vapor moved in the north for several nights would fulfil four criteria (night, north, motion, repetition), but can mean a comet (moving relative to the stars from night to night), or even a certain lunar halo phenomenon or a lunar fog bow (opposite of the moon and moving with the moon during each night, certain weather situations can support halo displays for several nights in a row); if it referred to an aurora, some mention of a color should be expected. While the number of criteria fulfilled gives some indication as to the likelihood that the event was an aurora, it does not quantify its strength. However, when using the aurora reports to investigate solar activity strength or to reconstruct the Schwabe cycle, using the more likely events (with more criteria fulfilled) is sufficient, while events with low or zero likelihood (e.g. white bands or white rainbows) are not helpful (see Neuhäuser \& Neuhäuser 2015a for examples).

$\mathrm{H}+15, \mathrm{H}+16$, and $\mathrm{K}+16$ do not discuss any criteria in sufficient detail. They largely avoid discussion of individual events or alternative interpretations of the records.

Furthermore, while $\mathrm{H}+15, \mathrm{H}+16$, and $\mathrm{K}+16$ do exclude observations explicitly reported for full daylight, they list observations at twilight, while Neuhäuser \& Neuhäuser (2015a) and Chapman et al. (2015) calculated during which twilight phase (civil, nautical, or astronomical) the sighting occurred at the given location and time. $\mathrm{H}+15$ and $\mathrm{K}+16$ do not indicate in their event tables, which observations were reported for night-time. Tamazawa et al. (2017) also claim to leave out day-time observations in their aurora list, but they do list many day-time sightings among their aurorae (our Sect. 3.3).

For likely true aurorae, quasi-simultaneous observations from other parts of the world provide additional information - this was not done in $\mathrm{H}+15$, but, e.g., in Willis et al. (2005) 
or Neuhäuser \& Neuhäuser (2015a), and to a limited extent in $\mathrm{K}+16$, but only with the Fritz (1873) catalogue.

$\mathrm{H}+15, \mathrm{H}+16$, and $\mathrm{K}+16$ provide only a few examples with Chinese text and full English translations. A list of Chinese texts is given only on their web page, but without English translations, while full original Chinese texts with full English translations are found elsewhere, e.g., in Keimatsu (1970, 1971, 1972, 1973, 1974, 1975, 1976), Xu et al. (2000), and Chapman et al. (2015).

It is of course useful to consider the lunar phase; however, giving a lunar phase for day-time observation, as e.g. in Tamazawa et al. (2017), is misleading. A peak of presumable aurorae around full moon (e.g. figure 3 in $\mathrm{K}+16$ ) shows that many non-auroral events are considered, so that more precise categorization should have been applied.

\subsection{Completeness}

The official Chinese dynasty reports on celestial phenomena are based on well-trained court astronomers, who use a similar protocol for reporting their observations, so that these records are more homogeneous than historical sources from other parts of the world, in particular Europe. From the fact that not all the solar eclipses, which could have been observed at the respective Chinese capital, are listed, it is clear that these compilations are not complete for day-time solar observations; and from the fact that not all the (observable) lunar eclipses are listed, it is also evident that the night-time observations are not complete - due to lost documents, overcast sky conditions, varying interest in certain phenomena, and maybe other biases (e.g. that the interpretation of an event was negative/unfortunate, so that the reporting was omitted/avoided for political or other reasons), so that it is always worth checking also other documents such as local records. The Qing dynasty source studied by $\mathrm{K}+16$ does include local observations outside the capital still, $\mathrm{K}+16$ notice (their section 3.3) that aurorae are completely missing for AD 1771-1814 (partly during the three very intense Schwabe cycles no. 2 to 4 at the end of the 19th century, partly already in the Dalton minimum). $\mathrm{K}+16$ did not find any naked-eye sunspot record in the Qing dynasty source, even though 44 Chinese naked-eye sunspots were previously published by others (e.g. Yau \& Stephenson 1988, Xu et al. 2000) for their study period (the time AD 1559-1912 according to their abstract), and also no sunspot nor aurora records corresponding to the Carrington event AD 1859 were found in $\mathrm{K}+16$.

There are two more reasons to study not only electronic copies of dynastic compilations: The records available nowadays are in most cases not the original manuscripts, but copies of copies of copies. It is well possible that scribal errors are hidden in the texts, and also dating errors (see, e.g., Chapman et al. 2015 for examples). In a digital search it may therefore easily be possible to miss a sunspot or aurora only due to a small scribal error, e.g. one transposed or missing letter or sign. In addition, local records often of- fer complimentary information to solve obvious scribal and dating errors.

In both old manuscripts and copies the dating can be off by anything between a day and years (e.g. Newton 1972). Manuscripts can have a known constant offset in years for a certain range of years (e.g. some versions of the Anglo-Saxon Chronicle around AD 774, see Neuhäuser \& Neuhäuser 2015b). East Asian chronicles like those studied by $\mathrm{H}+15, \mathrm{H}+16$, and $\mathrm{K}+16$ have the advantage that dates are often given in two systems, both on the lunar calendar (lunar month starting with conjunction of Moon and Sun as true new moon) and the day number in their sexagenary cycle (counting the days from 1 to 60, then starting over again and again). In some cases, when, e.g., a sexagenary day is given which did not exist in the given lunar month, it is likely that the lunar month (or year) is off by usually one month (or year), or there is a mistake in the sexagenary day, e.g. a scribal error (see Chapman et al. 2015). While e.g. Yau \& Stephenson (1988) and Xu et al. (2000) notice such cases and suggest corrections, $\mathrm{H}+15, \mathrm{H}+16$, and $\mathrm{K}+16$ do not discuss such problems individually, but instead seem to always give the given month (or year) only without day/date, instead of correcting the date. They also neither cite nor discuss the corrections in scholarly publications. See below for examples.

Also, studying whether there are quasi-simultaneous observations of both sunspots and aurorae within a few days is useful to cross-check the reliability of such records (they are often related to each other) including the dating accuracy, as e.g. done by Willis et al. (2005). H+15 would have had the possibility to check for quasi-simultaneous observations of both phenomena easily in their database, as they list both sunspots and aurorae. There are two such instances in the study by Willis et al. (2005) within the time period studied by H+15, namely AD 1137 Mar and AD 1193 Dec. For these dates, both the spots and the aurorae are listed by $\mathrm{H}+15$ as having been seen within a few days of one another, but it is not mentioned that the events were quasisimultaneous. While $\mathrm{K}+16$ did not find naked-eye sunspots in the Qing dynasty source (early 17th to early 20th century), it would have been possible to compare their presumable aurorae to (well-dated) telescopic sunspot observations; $\mathrm{K}+16$ do search for simultaneous aurora observations outside China, but only with the catalogue by Fritz (1873), which also does include non-auroral events.

Hence, limiting a study to the official treatises and a blind electronic search significantly limits the results.

Hayakawa et al. (2017b) argue that extending our survey to these [other, local, etc.] records ... can easily overestimate the actual amount of observations ... including other kinds of records without any criteria can make us overrate or underrate solar activity by this bias how many historical sources are still available today (their section on Historical documents for additional discussion). Apart from the fact that one should not search without any criteria, the official histories have different grades of completeness for differ- 
ent epochs and dynasties, and extending the survey to other documents alone cannot overestimate solar activity, but in all such studies, it is necessary to consider the completeness of the records, e.g. by comparing to the completeness of comet or eclipse reports (e.g. Strom 2015, Neuhäuser et al., in prep.).

\section{Comments on recent searches for aurorae and sunspots from different dynasties}

In this section, we comment on recent uncritical applications of the automatic search technique for aurorae and sunspots in the Chinese text corpus.

\subsection{Song dynasty AD 960-1279 (Hayakawa et al. 2015)}

First, we will discuss sunspots, then aurorae as presented by Hayakawa et al. (2015, henceforth $\mathrm{H}+15$ ).

\subsubsection{Sunspot records in Hayakawa et al. (2015)}

There are inconsistencies between the two sunspot quotations (a) and (b) in $\mathrm{H}+15$, as quoted in their section on sunspot records, and their own table 1 (on sunspots):

Instead of a spot for AD $1077 \mathrm{Jan} 11(\mathrm{H}+15$ quotation (a): in the sun were black spots ... They disappeared on 22, (i.e. plural spots), there is an entry for a spot in their table 1 for AD 1079 Jan 11 for 12 days (i.e. Jan 11-22) with no entry in the column on counts (indicating one spot); Xu et al. (2000) list two similar entries from Song Shi, use singular spot in their translation, and give AD 1079 Jan 11-22 as date range (but none in $\mathrm{AD} 1077 \mathrm{Jan}$ ).

Instead of a spot on AD 1145 June $(\mathrm{H}+15$ quotation (b) without day/date: in the sun were black vapors, i.e. plural), there is an entry in their table 1 for AD 1145 July (without days/dates) with black vapor (in addition to another entry for AD 1145 July for black spot), again without entry in the column of counts. Yau \& Stephenson (1988) mention a possible scribal error as reason for the date problem in AD 1145 June/July; Xu et al. (2000) then suggest July 23 as date for black vapor, for which both Yau \& Stephenson (1988) and Xu et al. (2000) use singular. While the two latter (older) publications indicate that this spot was seen for two days, $\mathrm{H}+15$ does not mention this duration (neither in the quotation nor in their table 1), even though it is found in the Song Shi, their source.

$\mathrm{H}+15$ should have compared their sunspots and their translations with previous publications, e.g. Keimatsu (1974, 1975, 1976), Wittmann \& Xu (1987), Yau \& Stephenson (1988), Xu et al. (2000). We note the following differences to $\mathrm{Xu}$ et al. (2000), the latest compilation:

While $\mathrm{H}+16$ list a record for 974 March without day/date, other publications give 974 Mar 3 as date (the Song Shi incorrectly gives 1 st month, but it was the 2 nd month, e.g. Xu et al. 2000).
For AD 1005 Feb 6, H+15 give shade, Counts: 2, and crescent-like shape (their table 1). The original Chinese text (given only on their web page) was translated by us to: In the sun there were two shades, shaped like crescents (Chinese text in our Fig. 1). This wording was otherwise not used for likely true sunspots. Hirayama (1889) gave fleckles for AD 1005 Jan 10 (no source given), which may be the same observation, but dated about one lunar month earlier; on $\mathrm{AD}$ 1005 Jan 13, there was a total solar eclipse visible in China, so that what was interpreted as spots by $\mathrm{H}+15$ and Hirayama (1889) may be a corrupt report of an eclipse.

For AD 1079, H+15 list two records from the Song Shi, one for Jan 11-22 and one for Mar 20 only, both presenting a plum, while others list the latter one to last until Mar 29 based on the Song Shi (Xu et al. 2000).

The record for AD 1103 Jul 1 reads The sun was weak and without light (listed in $\mathrm{H}+15$ in and below table 1), so that it could indicate haze or dust due to a volcanic eruption or a period of somewhat overcast days during which the sun barely appears through a thin layer of cloud. We found the entry for this event in Song Shi 52.1087 (Chinese text in our Fig. 1): On the guimao (40) day in the fifth month of the second year of the Chongning reign period (1 Jul 1103), the sun was faint red and without light; the word red was omitted in the $\mathrm{H}+15$ translation; this record is not listed in other recent compilations of sunspots.

The record for $\mathrm{AD} 1104 \mathrm{Nov}$ (renchen day ... within the sun there was a black spot, as large as a jujube, i.e. a date, our translation of the Chinese text in Fig. 1) is also not listed in any other catalogues for that date. It is based on Song Shi $w u$ ch. 52, where the date is incorrectly given as Emperor Huizong of Song, 3rd year of the Chongning reign period, 10th month, day ren-chen (29), which should be 4th year as in Song shi yi ch. 20, as specified in Xu et al. (2000), there was no renchen day (29) in the 10th month of the 3rd year. Hence, the correct date is AD 1105 Dec 6 (Xu et al.: There was a black spot in the sun as large as a date). Based on the above mentioned record from Song shi yi ch. 20, H+15 uncritically adopt and list the date given there, too, namely AD 1105 Nov 6 (as in Keimatsu 1975), but the date has to be corrected to AD 1105 Dec 6; see e.g. Xu et al. (2000).

The spot given for AD 1137 Mar 11 only $(\mathrm{H}+15)$ was observed from Mar 1-11, e.g. Xu et al. (2000).

In $\mathrm{AD} 1137, \mathrm{H}+15$ give a record for May 8 until 22; the translation in Xu et al. (2000) dated AD 1137 May 8 reads: There was a black spot on the Sun that lasted through the 5th month, when it dissipated, the 5th month being May 22Jun 19 according to Xu et al. (2000). It may not be justified to limit the visibility of the spot to May $22(\mathrm{H}+15)$, when the 5th lunar month just started, as it may be unlikely to detect a spot on 15 subsequent days by naked eye; at least one more (later) spot could be involved given the wording through the 5 th month.

The event listed by $\mathrm{H}+15$ dated 1139 Mar ... for a month can better be dated Mar 3 to Apr 1 and was observed for more than a month (e.g. Xu et al. 2000). 
Candidates from Hayakawa et al. $(2015, \mathrm{H}+15)$ in our Sect. 3.1:

Sunspot candidate 1005 Feb 6 (Song shi 52.1086):

景德元年十二月甲辰, 日有二影, 如三日狀。

Jingde yuan nian shier yue jiachen, ri you er ying, ru san ri zhuang.

Aurora candidate 1006 Apr 14 (first) (Song shi 64.1411):

景德三年三月丙辰, 北方 赤氣互天。

Jingde san nian san yue bingchen, bei fang chi qi gen tian.

Aurora candidate 1006 Apr 14 (second) (Song shi 60.1308) :

景德 $\cdots$ 三年三月丙辰, 北方赤氣亘天, 白氣貫月。

Jingde... san nian san yue bingchen, beifang chi qi gen tian, bai qi guan yue.

Aurora candidate 1006 May 9 (Song shi 60.1308):

景德三年…四月癸卯, 黃氣如柱貫月。

Jingde san nian... si yue guimao, huangqi ru zhu guan yue.

Aurora candidate 1019 May (23?) (Song shi 60.1309):

天禧三年四月, 黃氣如柱貫月。

Tianxi san nian si yue, huang qi ru zhu guan yue.

Sunspot candidate 1103 Jul 1 (Song shi 52.1087):

崇寧二年五月癸卯, 日淡赤無光。

Chongning er nian wu yue guimao, ri dan chi wu guang.

Sunspot candidate 1104 Nov (Song shi 52.1087):

崇寧…三年十月壬辰, 日中有黑子如霜大。

Chongning... san nian shi yue renchen, ri zhong you heizi ru zao da.

Aurora candidate 1119 Aug 21 (Song shi 60.1314):

宣和元年 $\cdots$ 七月戊午夜, 赤雲起東北方, 貫白氣三十餘道。

Xuanhe yuan nian... qi yue wuwu ye, chi yun qi dongbei fang, guan bai qi sanshi yu dao.

Aurora candidate 1204 Mar (Song shi 64.1413):

嘉泰四年二月庚辰夜, 有赤雲間以白氣, 東北互天, 後八日國有大火, 占者以為火祥。

Jiatai si nian er yue gengchen ye, you chi yunjian yi bai qi, dongbei gen tian, hou ba ri guo you da huo, zhan zhe yi wei huo xiang.

Fig. 1 Here, we show the Chinese texts related to some of those events reported by Hayakawa et al. (2015), which we discuss in our text. Translation and discussion are given in the Sect. 3.1. 
The two entries for AD 1145 July in $\mathrm{H}+15$ (without day/dates), one on a black vapour and one on a black spot, were dated July 23 and 24, respectively, in, e.g., Xu et al. (2000), who remarks that what is given as 6th month in the Song Shi should be 7th month; it is probably this correction that was not noticed by $\mathrm{H}+15$, so that they did not give a day at all.

For AD 1185, H+15 list one spot for Feb 10, one from Feb 15 to 27 (also in Xu et al. 2000), and one more for Feb 27, but do not mention that a spot was also seen on Feb 11 in Korea (Lee et al. 2004).

For AD 1186, H+15 list one spot each for both May 23 and 26 for one day each, while Xu et al. (2000) show that the spot lasted from Mar 23 through Mar 27.

Almost all the sunspot records listed by $\mathrm{H}+15$ (their table 1) were presented before by others as sunspots; relevant literature such as $\mathrm{Xu}$ et al. (2000) is not cited in the paper. $\mathrm{H}+15$ provide the original Chinese only on their web page, without English translation. The new records are questionable and probably due to other phenomena, not spots, e.g. sun was weak and without light.

\subsubsection{Aurora records in Hayakawa et al. (2015)}

First, we consider aurora examples highlighted in $\mathrm{H}+15$, then discuss some general problems of their work related to aurorae, and finally touch briefly aurorae around AD 993/4 (Hayakawa et al. 2017a).

In their example quotation (a) for aurorae, listed in their section on methods, $\mathrm{H}+15$ present an aurora with a different translation compared to previous catalogues:

H+15 translate Song shi (Five Phases II b, p. 1413) as follows:

on - March CE 1204 at night, red clouds appeared within white vapors, crossing the sky from the east to the west. After that, conflagrations occupied the country for eight days. Thus, astrologers regarded this as a symbol of fire.

While the same Chinese text was interpreted as aurora before by others, their translations differ. Yau et al. (1995) dated the event to AD 1204 Mar 29 and translated (brackets their additions):

(i) Chia-t'ai reign period, 4th year, 2nd month, day kengshen (57). At night, a red vapour extended across the sky (Song Shi 38) and

(ii) Chia-t'ai reign period, 4th year, 2nd month, day kengch'en (17) (should read keng-shen as in preceding entry). At night, a red vapour mixed with a white vapour was stretching across the N sky (Song Shi 64).

$\mathrm{Xu}$ et al. (2000) translate the event dated AD 1204 Mar 29 as follows (square brackets their addition):

Emperor Ningzong of Song, 4th year of the Jiatai reign period, 2nd month, day gengshen [57]. During the night, there was a white vapor among the scarlet clouds that extended across the northeast sky (Wenxian tongkao ch. 298).

The text fulfils three aurora criteria from Neuhäuser \& Neuhäuser (2015a): night-time, partly northern direction, and red color. AD 1204 Mar 29 is only a few days before the new moon of Apr 2.

We see that the older translation used the traditional Wade-Giles system for romanizing Chinese characters. More significantly, we also see that both Yau et al. (1995) and $\mathrm{Xu}$ et al. (2000) date the event to AD 1204 Mar 29, while H+15 only give 1204 March in their quotation (a).

While H+15 translate Song shi 64.1413 from the east to the west, Yau et al. (record ii) give across the north sky. The original Chinese text (see our Fig. 1) does not contain the phrase from the east to the west, $\mathrm{H}+15$ misread north for west, the specified direction is NE. The entry mentions red yun (cloud) and white qi (vapor), both for the gengchen night in the 2nd month, i.e. Mar 29.

Quotation (a) in $\mathrm{H}+15$ above gives east to the west as direction, while their own table 2 gives east-north for this event (1204 Mar without day), the direction from Xu et al. In their table 2, there is another event dated AD 1204 Mar 29 (red vapour) without direction, obviously a duplication (see Yau et al. record i). Keimatsu (1976) also listed this event for AD 1204 Mar 29 (as certain aurora), but without translation (published by Fukushima after Keimatsu had passed away). H+15 even goes as far as claiming that this particular aurora (dated AD 1204 Mar without day/date) lasted for eight days (their table 2), even though this is not specified in the record; the record in fact states that afterwards conflagrations occupied the country for eight days.

In their example quotation (b) for aurorae (AD 1119 Aug 21), listed in their section on auroral records, $\mathrm{H}+15$ present an event where their English translation does not include the word night, even though the Chinese text (our Fig. 1) does include the word for night. Keimatsu (1975), Yau et al. (1995), and Xu et al. (2000) all list this event and do include its night-time occurrence in their translations. Table 2 in $\mathrm{H}+15$ lists only north for this event, while the quotation (b) in their section on auroral records gives northeast. Keimatsu (1975), Yau et al. (1995), and Xu et al. (2000) all give northeast. The translation in $\mathrm{H}+15$ says: red clouds appear [qi] in the NE direction running through 30 ways of white vapors (at night). Other translations of the same Chinese entry (Keimatsu 1975, Yau et al. 1995, Xu et al. 2000) used rose or arose correctly for the verb qi instead of appear (which would be xian). This fulfils the aurora criteria night, partly north, and red, but it happened shortly before full moon (new moons were AD 1119 Aug 8 and Sep 6, Gautschy 2014). As the moon rose that night in the ESE as seen from Kaifeng, the northern Song capital, a lunar halo display is less likely.

Classical Chinese often does not distinguish between passive and active senses of a verb, as is the case with penetrated here (translation from Xu et al. 2000 instead of running through as in $\mathrm{H}+15)$. The lines in question might be rendered in two ways, as is the case above. We suspect that the more than thirty 'ways' refers to shafts of light (qi can refer to light; the convenient translation vapors may well be leading us astray here). Way is a dao, which means in its 
basic sense a road, and is here used to denote something long and thin. Penetrated should probably be understood in the passive, as something long and thin can penetrate a cloud, while it is hard to imagine a cloud penetrating something long and thin. We therefore translate: On the night of the wuwu day in the seventh month, red clouds arose in the northeastern direction and were penetrated by more than thirty shafts of white qi (qi here seems to mean light).

In their table $2, \mathrm{H}+15$ provide only a few keywords from their English translations, but not the full text; the original Chinese is given only on their web page, without English translations nor references to previous work. It would have been beyond the scope of our paper to compare the translations by $\mathrm{H}+15$ or $\mathrm{K}+16$ (the keywords in their tables) with all previously published translations, e.g. by Matsushita (1956), Keimatsu (1970, 1971, 1972, 1973, 1974, 1975, 1976), Yau et al. (1995), or Xu et al. (2000), such a comparison should have been done by $\mathrm{H}+15$ and $\mathrm{K}+16$.

Duplications are also a problem: while $\mathrm{H}+15$ list two aurorae with the same details for AD 979 May 9 and 19 (their table 2), Yau et al. (1995) mentioned that it is one event on either May 9 or 19. Other duplications are 986 Feb 22 plus one in $986 \mathrm{Feb}$ (without day), both red vapor in Kaifeng. The event listed for 1007 May 13 reports a band of white vapor covering the moon (probably a halo phenomenon) 1

Table 2 in $\mathrm{H}+15$ on aurorae implies that all events reported would be auroral records, but in fact they are somewhat luminous, partly colorful events at night or around twilight (dusk or dawn), not all such events are necessarily aurorae.

We will now consider four more presumable aurorae listed in table 2 of $\mathrm{H}+15$ (Chinese text in our Fig. 1), somewhat related to each other, which were previously discussed in Neuhäuser et al. (2017): there are two entries for $\mathrm{AD}$ 1006 Apr 14 (brackets are our additions, but as meant in H+15): 1006 Apr 14 R[ed] V[apour] n[orth] [in] Kaifeng [lunar phase] 0.46 and $1006 \mathrm{Apr} 14$ W[hite] V[apour] near the moon [in] Kaifeng [lunar phase] 0.46 (0.46 means near full moon). One of the two texts is from the astronomical treatise (Tianwen zhi) of the Song Shi, the other from its treatise on general omenology (wuxing zhi). Xu et al. (2000) combine red and white vapor to one text and then also give Song shi Tianwen zhi 60 and wuxing zhi 64 . The two original sources read:

On the bingchen day of the third month of the third year of the Jingde reign period, northern direction, red qi spread across the sky (Song shi 64.1411) and

On the bingchen day of the third month of the third year of the Jingde reign period, northern direction, red qi spread

\footnotetext{
1 While Hayakawa et al. (2017b) write about their aurora YS\#A1 that Yau et al. (1995) and Xu et al. (2000), with its date as 1262.02 .09 mistakenly, and we should correct this to the same date in 1261 (end of their section 3), we would like to note that Xu et al. (2000) dated this entry to AD $1261 \mathrm{Feb} 9$. Abbott \& Juhl (2016) also list this event as aurora for AD $1261 \mathrm{Feb} 9$, and comment N[not] I[n] Y[au], while it is in Yau et al. (1995) under AD $1262 \mathrm{Feb} 9$.
}

across the sky. White qi penetrated the moon. (Song shi 60.1308).

It is very unlikely that the white vapour near the almost full moon is an aurora (more likely some halo effect). If the red vapour was far away from the moon or when the moon was below horizon, then it could have been an aurora.

There is an additional entry in table 2 of $\mathrm{H}+15$ : 1006 May [without day] Y[ellow] V[apour] near the moon [in] Kaifeng, also from Song Shi 60.1308; our translation of this entry in AD 1006 is: On this date (guimao, 40) yellow qi like a pillar penetrated the moon; hence, this is also not an aurora. The date for this event is uncertain: as it is given as the guimao (40) day in the fourth month, when in fact there was no guimao day in the fourth month; a guimao day did occur at the beginning of the fifth month (1006 May 31) and at the beginning of the third month (1006 Apr 1). Both are, however, so close to new moon that the text (penetrated the moon) does not fit to the given sexagenary date. There is another instance of the same phrase (yellow vapour like a pillar penetrated the moon) dated to the 4th month of the 3rd year of the Tianxi reign period (AD 1019) given without the guimao date - even though there is a guimao date in that month (AD 1019 May 23, close to full moon on May 21/22). It is possible that the event somehow got transposed to the wrong reign period (Neuhäuser et al. 2017).

H+15 list Y[ellow] V[apour] for 1019 May 8. The text does not specify a particular day; May 8 is the first day of the month. They omitted the wording penetrated the moon, which is clearly given in the original Chinese (see our Fig. 1); $\mathrm{H}+15$ give 0.04 as lunar phase (new moon May 7), so that again the text (penetrated the moon) is not consistent with the lunar phase for the date given in $\mathrm{H}+15$. This event was most probably a lunar halo pillar rather than an aurora (Neuhäuser et al. 2017).

Of the four entries in $\mathrm{H}+15$ for AD 1006 Apr 14 red, AD 1006 Apr 14 white, AD 1006 May yellow, and AD 1019 May 8 yellow, only the first may be an aurora. The remaining three are given as moon-related phenomena. Moreover, the last two have dating problems and were probably a single event (wrong date in $\mathrm{H}+15$ ).

The Chinese linear measurements cun, chi, and zhang are often used to describe the length of celestial objects, such as comets tails. They also tend be used for approximations and are frequently prefaced with the word $k e$ (about). $\mathrm{H}+15, \mathrm{H}+16$, and $\mathrm{K}+16$ wrote that it is unknown which angle in the sky these measurements refer to. However, this is well known, as most recently given in Chapman et al. (2015) and references therein: A chi is one degree when referring to astronomical objects (angle in the sky), see Ho Peng Yoke (1962); otherwise for terrestrial linear measures it is one foot or $25 \mathrm{~cm}$ (but varying somewhat in time, e.g. $33 \mathrm{~cm}$ in Tang times). A zhang is either ten Chinese feet for general linear measurements, or ten degrees as angle on sky in astronomy (Wilkinson 2000; Wang 2008). A $d u$ is a Chinese degree, where our (i.e. the Babylonian) 360.00 degrees 
correspond to 365.25 Chinese degree $(d u)$, one $d u$ is then 0.98562 degree.

The presumable aurorae plotted in figure 3 in $\mathrm{H}+15$ do not correspond to the aurora dates listed in their own table 2 : e.g., the first plotted aurora is missing in their table, while other early aurorae listed in the table are not plotted. The caption to their figure 3 speaks about 774, while the figure covers a few decades around AD 1000.

Figure 4 in $\mathrm{H}+15$ as well as figures 4 and 5 in Hayakawa et al. (2017b) show the distribution of their presumable aurorae with lunar phase. One would expect a broad minimum around full moon (phase 0.5), because aurorae can better be found in dark nights. These figures do not show such a drop, which indicates that there are probably lunar-related phenomena in their data set (seen around full moon). It also is not useful to correlate a sample with twilight observations with the lunar phase: e.g., in $\mathrm{H}+15$, at least 25 of the 193 entries in their table 2 are during sunrise, sunset, or dusk.

The period studied in $\mathrm{H}+15$ starts with AD 960 and therefore includes the $\mathrm{C} 14$ variation around AD 994. They write that they did not find any candidates of sunspot nor aurora in these years [AD 993-994] and that they found a cluster of auroral candidates several years after this event. The closest aurora recorded is in 996 and there is a record of a sunspot in CE 1005 (H+15 for Song shi). Then, Hayakawa et al. (2017a) re-investigated possible aurorae from AD 990 to 994. They argue that no Chinese observations of aurorae from AD 988 to 996 could be due to bad weather or lost records; however, we note that there were several lunar eclipses observed in China from AD 991 to 995 (e.g. Xu et al. 2000) plus comet Halley in AD 989 with many Chinese records (e.g. Ho Peng Yoke 1962), so that celestial observations are extant.

Hayakawa et al. (2017a) found in Fritz (1873) and Link (1962) a few European sightings (which may be likely true aurorae) and also an event in Korean records between 992 Dec 26 and 993 Jan 25 (12th month in 11th year of Seongjong): At night, heaven's gate opened (their section 3.4). Only the night-time criterion is fulfilled; the date range for the relevant lunar month was incorrectly given as 992 Dec 27 to 993 Jan 15 in Hayakawa et al. (2017a), four times in their section 4 (the correct date range is 992 Dec 26 and 993 Jan 25). The event listed for AD 992 Dec (without day) as $R[e d]$ in Lee et al. (2004) from Korea may be meant to be the same record, but the text does not give any color. While Yau et al. (1995) still included it in their aurora catalogue, Stephenson (2015) re-considered whether this Korean sighting could be auroral: somewhat vague Korean allusion around the end of 992 or the start of 993 (his section 5.3).

A drawing of a presumably similar event reported as heaven's split (translation in Hayakawa et al. 2017a) in a Chinese divination manual shown in their figure 3 (Hayakawa et al. 2017a) does not support an auroral interpretation, partly because the drawing is fully consistent with a halo phenomenon or a fog bow: a white band or bow seems to touch the landscape (like a typical fog bow), and the text accompanying it also does not present any auroratypical wordings such as $q i$ (vapor) nor other aurora criteria. As the surrounding text depicted in Hayakawa et al. (2017a) reveals, the Goryeosa (History of Goryo) astronomical treatise in which the event is recorded is highly variegated. The record stating that heaven's gate opened occurs alongside entries for comets, meteors, planetary conjunctions, eclipses, and other phenomena. The absence of divisions between various types of events makes it particularly difficult to deduce what the phrase heaven's gate opened meant or what sort of phenomenon it described.

Hayakawa et al. (2017a) conclude from the equatorward boundary of the aurora oval (i.e. from the dubious Korean sighting) on the strength of the geomagnetic activity (Dst index): Although the estimated Dst is a crude approximation and a careful diagnosis necessary, there is a possibility that the magnetic storm that occurred in the period between 992.12.27 and 993.01.15 was a stronger storm than any of the storms recorded since 1957 (Hayakawa et al. 2017a, their section 4.2), with one of the incorrectly given month ranges. Hayakawa et al. (2017a) then speculated whether there was a series of several large coronal mass ejections within one month. There were in fact several likely true aurorae in AD 992 Apr, Oct, and Dec in northern and central Europe, indicating a solar activity level which is not exceptional (see also Stephenson 2015 and Neuhäuser \& Neuhäuser 2015c). Since it is dubious to interpret this Korean record as an aurora, it is not justified to deduce the Dst index or storm strength from this observation - it does not even indicate a storm. There is no evidence for an exceptional solar super-flare, e.g. the fact that no sunspot was recorded for that time, in particular no evidence for the 2nd strongest solar flare in millennia as claimed by Mekhaldi et al. (2015). Also Stephenson (2015) concluded that the 990ies are not unusual regarding auroral frequency.

\subsection{Aurorae records from the Qing dynasty in Kawamura et al. (2016)}

Kawamura et al. (2016, henceforth $K+16)$ searched in the Qing shi gao (Draft History of the Qing Dynasty) (specified in $\mathrm{K}+16$ as AD 1559-1912 or 1616-1912 (their section 1), or 1644-1912 (their section 4), in their table 1, entries range from 1613 to 1876, plus two without years; this dynasty ruled from AD 1616-1911 according to Xu et al. 2000); note that the standard date for the beginning of the Qing is 1644.

$\mathrm{K}+16$ found 111 entries listed as aurora candidates in their table 1, of which 77 are white. They then exclude those 26 cases, where the observation was longer than 4 days, which could be comets. In their table 1, there is one more entry (no. 5 in AD 1618) for 16 days, which is not listed among the excluded ones (end of section 3.2); apparently, $\mathrm{K}+16$ did not compare their event list with comet catalogues 
like Ho Peng Yoke (1962) or Kronk (1999), but simply mention the comets of AD 1668 and 16802

Among their 14 primary aurorae listed in their section 3.5 with simultaneous observation in Fritz (1873) on the same day or one day before (K+16, their section 3.5), but not being a comet, five are about the event AD 1770 Sep $17+18$, for which the aurora detection in China itself is also mentioned in Fritz (1873). K+16 do not mention other publications, which already presented some of these aurorae; e.g. the Yau et al. (1995) catalogue extends to AD 1770, but includes only two of the seven different events from $\mathrm{K}+16$ (until AD 1770) as aurorae (AD 1730 Feb 15 and AD 1770 Sep $17+18$ ), because important aurora criteria are not fulfilled: e.g. the event on AD 1754 May 8 is likely a lunar halo display close to full moon (white band from $S E$ to $W$ ), close to the Schwabe cycle minimum in AD 1755.2; those on AD 1853 Apr 23 and AD 1868 Oct 30 neither give northern direction nor night-time, and are therefore dubious as aurora candidates.

Among their 14 primary aurorae, five are on the same date and one of them plus five others do not mention nighttime $(\mathrm{K}+16$ section 3.5). Of course, it is not useful to study the lunar phase distribution of events, for many of which there is no evidence that they were at night, so that their figure 3 is useless.

Among the non-primary candidates, $\mathrm{K}+16$ select those five records (two on the same date) with a lunar phase between 0.0 and 0.1 or between 0.9 and 1.0 as secondary candidates (their section 3.6). Only one of these five records is listed in Yau et al. (1995), namely the one on AD $1618 \mathrm{Jul}$ 19, for which Neuhäuser \& Neuhäuser (2016) noticed that it is simultaneous to the sunspot drawn by Malapert for AD $1618 \mathrm{Jul} 7$ to 19. Among those five records, four are within the Maunder Minimum on three different dates: AD 1650, 1667 , and 1679. None of them are listed in any other East Asian aurora catalogue, possibly because none of those reports mention night-time (two white vapor and one band of white light without direction), which could be atmospheric optical effects.

$\mathrm{K}+16$ also compare their presumable aurorae with sunspots and the sunspot Schwabe phase in their figures 1 and 2; however, since there are many non-auroral events in their sample, it is not surprising that the auroral distribution

\footnotetext{
2 Also, Hayakawa et al. (2017b) list at least two well-known comets as aurora candidates: MS\#A10 is comet C/1618 V1 as given in Ho Peng Yoke (1962) and Kronk (1999) (Hayakawa et al. 2017b: the records are maintained on the list [of aurorae] regardless of their degree of reliabilities, end of their section 3) and YS\#A11 (AD 1362), for which Hayakawa et al. (2017b) only write we must not exclude the possibility that this was a comet (their section 4), but they did not consult, e.g., Ho Peng Yoke (1962) nor Kronk (1999), where it is given as comet for 40 day with long tail, partly in the same constellations as listed by Hayakawa et al. (2017b) for the presumable aurora. Abbott \& Juhl (2016) also list several well-known comets in their aurora catalogue, e.g. the comet of AD 1695 Nov, which is observed in the same constellations Crv and Hya as listed for the presumable aurora (e.g. Kronk 1999); the comet of AD 1529 Feb (only one observation with a long tail in Kronk 1999) is listed in 11 entries in Abbott \& Juhl (2016), namely from AD 1529 Jan 26 to Feb 8, as white vapor(s), partly in the SW, up to $60^{\circ}$ long (not an aurora, but the comet tail).
}

does not follow the sunspot Schwabe cycle phase (their figure 2). There are almost no aurorae in the rising part (phase 0.2-0.4), but 17 events are seen at minimum (phase 0.0-0.1 or 0.9-1.0), including 15 white ones.

\subsection{The period AD 581-959 (Tamazawa et al. 2017)}

First, we will discuss aurorae, then sunspots as presented by Tamazawa et al. (2017, henceforth T+17).

\subsubsection{Aurora records in Tamazawa et al. (2017)}

We will study a few aurora examples given in Tamazawa et al. (2017; $\mathrm{T}+17)$. Then, we present English translations of many of their presumable aurorae (showing that several were at day-time).

$\mathrm{T}+17$ used the same method as $\mathrm{H}+15$ to search for aurorae and sunspots in the period AD 581 to 960 (according to their section 2.1, but up to AD 959 according to their title; auroral records in their table 1 start in AD 511; sunspot records in their table 4 start at AD 567). Their discussion includes records of vapor, cloud, light with color and remove (d) unsuitable ones (e.g. those observed during daytime and so on). Because it is not clear what specific criteria they used, their work is not reproducible (their section 2.2). They then wrote that Keimatsu listed all the luminous phenomena seen at night ... However, Yau (1995) indicated that Keimatsu's work mistakenly included comets or shooting stars ... Therefore, we assume that the records of luminous phenomena observed at night are potentially those of auroras (their section 2.2.2).

In their example EX3 (their section 2.2.2), T+17 include the report for AD 776 Jan 12; there are three different datings in the literature, but after a careful philological and astronomical analysis, Chapman et al. (2015) found AD 776 Jan 12 to be the only intrinsically correct one; this date is also listed in $\mathrm{T}+17$ (without mentioning a reasoning). The sequence of constellations given are those on or close to the path of the moon that night (very close to full moon), so that Chapman et al. (2015), after a detailed discussion, considered it non-auroral and as a probable halo display (T+17 only cite Xin Tang shu, not Jiu Tang shu, and do not discuss the differences in their translation compared to several previous publications). In their section 3.4.1, T+17 acknowledge that this observation was east-south-west. In their table 2, however, they only give west; the translation in $\mathrm{T}+17$ gives in the eastern sky. Since the phenomenon was seen above the roughly full moon only in the first half of the night, it was only in the east and south, see Chapman et al. 2015). They further write white vapor was seen in the area whose elevation angle was up to 40-90 degrees ... this record cannot be explained by lunar halos ... neither with a radius of 22 nor 46 degrees; however, as seen from Chang'an (modern Xi' an), the Chinese capital at that time, the moon itself rose up to 75 degrees above the horizon. Even the rising moon can generate halo displays that reach 
Aurora candidates discussed in our Sect. 3.3 regarding Tamazawa et al. (2017):

604 Jan 21 (Suishu 69.1613)

仁壽三年...十二月十五日夜, 通漢鎮北有赤氣亘北方, 突厥將亡之應也。

Renshou sannian ... shier yue shiwuri ye, Tonghan zhen bei you chi qi gen beifang, Tujue jiang wang zhi ying ye.

744 Feb 3 (Xin Tangshu 32.836)

天寶三載正月庚戌, 月有紅氣如垂帶。

Tianbao san zai zheng yue gengxu, yue you hong qi ru chui dai.

761 Dec 13 (not 756 as misdated in $\mathrm{T}+17)$ (Xin Tangshu 32.836)

肅宗元年建子月癸巳乙夜, 月掩昂而暈, 色白, 有白氣自北貫之。

Suzong yuan nian jianzi yue guisi yiye, yue yan mao er yun, se bai, you bai qi zi bei guan zhi.

761 Dec 13 (Xin Tangshu 33.856)

上元... 三年建子月癸巳, 月掩昂, 出昂北。

Shangyuan ... san nian jianzi yue guisi, yue yan mao, chu mao bei.

761 Dec 13 (Jiu Tangshu 36.1325)

其年建子月癸巳亥時一鼓二籌後，月掩昂，出其北，兼白暈；畢星有白氣從北來貫昂。

Qi nian jianzi yue guisi hai shi yi gu er chou hou, yue yan mao, chu qi bei, jian bai yun; Bixing you bai qi cong bei lai guan mao.

767 Aug 17 (Jiu Tangshu 36.1342)

大曆...二年七月 ...丙寅申時，有青赤氣長四十餘尺，見日旁，久之乃散。

Dali ... er nian qi yue, bingyin shenshi, you qing chi qi chang sishi yu chi, xian ri pang, jiu zhi nai san.

767 Aug 23 (Jiu Tangshu 36.1342)

大曆…云年七月 ...壬申十二月, 赤氣長二丈互日上。

Dali ... er nian qi yue ... renshen shier yue, chi qi chang er zhang gen ri shang.

767 Oct 25 (Jiu Tangshu 36.1326)

大曆…元年...九月 ....亥, 青赤氣互于日旁。

Dali ... er nian ... jiu yue ... yihai, qing chi qi gen yu ri pang.

829 Sep (Xin Tangshu 35.924)

大和三年八月, 西方有白氣如柱。

Dahe san nian ba yue, xifang you bai qi ru zhu.

833 Nov 17 (Xin Tangshu 35.924)

大和...七年十月已酉，西方又有白氣如柱者三。

Dahe ... qi nian shi yue yiyou, xifang you you bai qi ru zhu zhe san.

893 Nov (Xin Tangshu 32.836)

景福二年十一月, 有白氣如環, 貫月, 穿北斗, 連太微

Jingfu er nian shiyi yue, you bai qi ru huan, guan yue, chuan Beidou, lian Taiwei.

901 Oct 5 (Xin Tangshu 35.925)

天復元年八月己亥，西方有白雲如履底，中出白氣如匹練，長五丈，上衝天，分為三彗，頭下垂。

Tianfu yuan nian ba yue yihai, xifang you bai yun ru lüdi, zhong chu bai qi ru pi lian, chang wu zhang, shang chong tian, fen wei san hui, tou xia chui.

953 May (Jiu Wudai shi 110.1452)

三年三月... 一夕, 在山亭院齋中, 忽有黃氣起於前, 上際於天，帝於黃氣中見星文，紫微、文昌，爛然在目既而告之星者曰： 予於室中見天象，不其異乎？

San nian san yue... Yi xi, zai shan ting yuan zhai zhong, hu you huang qi qi yu qian, shang ji yu tian, di yu huang qi zhong jian xingwen, Ziwei, Wenchang, lanran zai mu. Ji er gao zhi xing zhe yue: Yu yu shi zhong jian tian xiang, bu qi yi hu?

New sunspot from Tamazawa et al. (2017), our Sect. 2.6, 840 Dec 28 (Xin Tangshu 32.834):

開成...五年...十二月癸卯朔, 日旁有黑氣來觸。

Kaicheng ... wu nian ... shier yue guimao shuo, ri pang you hei qi lai chu.

Fig. 2 Here, we show the Chinese texts related to some of those events reported by Tamazawa et al. (2017), which we discuss in our text - first their aurora candidates, at the end the one likely true new sunspot. Translation and discussion are given in the Sect. 3.4. 
the zenith. The event is not listed as an aurora in Yau et al. (1995) nor Xu et al. (2000).

For their example EX4, T+17 also only cite Xin Tang shu, but not the variants in Jiu Tang shu and Wenxian tongkao as cited in Chapman et al. (2015), who consider it a likely true aurora like Keimatsu (1973), Yau et al. (1995), and Xu et al. (2000), whose work again is not mentioned in connection to EX4 by $\mathrm{T}+17$.

$\mathrm{T}+17$ then highlight presumable quasi-simultaneous sightings of their aurora candidates elsewhere and quote in EX6 for AD 937 Feb 14 for Europe around the cockcrow continuously illuminated by day, bloody light appeared through all of sky (their section 3.1); while the original ... usque ad illucente die (Odericus Vitalis in Eccl. Historia, see Link 1962) should not be translated by day, but from around cockcrow (the first three hours after the middle of the night) and until the (first) daylight $\mathrm{T}+17$ translate at the end of the Chinese text for AD 937 Feb 14 (their EX5) with ... and disappeared at the dusk, while Xu et al. (2000), who bring two more reports, translate ... did not disperse until dawn (this Chinese text shows that aurora visibility ceases at the start of twilight). The translation by $\mathrm{T}+17$ is wrong: dusk is at sunset, dawn at sunrise. The listing for this event on AD 937 Feb 14 in their table 3 is then not consistent with their translation (vapor and direction are missing in their table).

$\mathrm{T}+17$ list 47 aurora candidates (with vapour, cloud, or light in their tables 1-3), which are distributed quite equally around the lunar phase (their figure 3). One would expect a peak around new moon, if these were mostly true aurorae, but many of their presumable aurorae are during the day (see below), so that the lunar phase is irrelevant.

In their section 3.4.1, T+17 discuss some of the observations considered by Chapman et al. (2015) as either misinterpreted or dubious aurorae, partly because they were reported at twilight and/or as white light near the moon. As a counter-argument, $\mathrm{T}+17$ again bring their example EX6, which ended around twilight. The second example given by $\mathrm{T}+17$ as counter-argument is a simultaneous sighting in China (T+17: at sunset) and Japan (T+17: at the beginning of night) on AD $1363 \mathrm{Jul} 30$; Xu et al. (2000) include in their translations for this date two white rainbows surged straight up (China, a halo display?) and as if there was a fire burning in the distance ... a sign of drought (Japan, a real wild fire or a deep red sunset?), so that these examples remain dubious.

The third example given by $\mathrm{T}+17$ for aurora seen at twilight is the Carrington event, which is widely considered a particularly strong solar storm, clearly very different from the descriptions considered as misinterpreted or dubious aurorae by Chapman et al. (2015). The arguments in $\mathrm{T}+17$ in favour of historical aurorae around twilight or full moon are misleading.

The aurora $\mathrm{T}+17$ present in section 3.4.4 for AD 763 Sep (as not listed in C[hapman et al. 20]15) is not new, but has appeared in previous scholarship. This record is translated in both Chapman et al. (2015) and Xu et al. (2000), where it is dated to AD 762 May 20 . We could identify the text $\mathrm{T}+17$ referred to only by referencing their web-based catalogue as they do not give an explicit reference in their article. We are uncertain as to how $\mathrm{T}+17$ arrived at the AD 763 Sep date.

Among the 59 aurora candidates listed in tables 1-3 in $\mathrm{T}+17$ (where the lunar phase is unnecessarily given to up to six digits), ten have rainbow as textual description, four were seen towards the south, and three are just some L[ight] $(\mathrm{T}+17$ tables $1-3)$, i.e. highly dubious, and most others were previously published $3^{3}$

Since it would be beyond the scope of this paper to translate and check each and every presumable aurora listed in $\mathrm{T}+17$, we present here just one case from the 9th century, which was previously published elsewhere:

AD 811 Mar 31: $T+17$ list only red vapor (their table 2); Keimatsu (1974) wrote a meteor ... fell down ... There was a red vapor like a standing snake, more than ten feet (degrees) long, upon the place where the star fell down, but it vanished in the evening ... doubtful. This sighting probably refers to a meteor, not an aurora, and even the red vapor like a standing snake is reported to have vanished in the evening, showing again how important it is to consider the context (i.e. the preceding and following sentences).

Tables 1-3 in $\mathrm{T}+17$ only present certain keywords, but not the full text nor the source. The Chinese text is found only on their webpage, but without English translation. Several of the events were clearly observed at day-time. All those events, which would be new (as yet unpublished) aurorae in their tables 1-3, but which are not only about some light or rainbow, were translated to English by us (Chinese texts in our Fig. 2). Only the first event can be considered as aurora:

604 Jan 21: On the night of the fifteenth day in the twelfth month of the third year of the Renshou reign period, north of Tonghan Garrison there was crimson qi that extended across the north. This was a response to the imminent fall of the Tujue. (Or possibly: This was a response to the death of the Tujue general). The text fulfils the aurora criteria night, crimson (reddish), north; however, it was on the 15th of the lunar month, i.e., on the night of a full moon.

744 Feb 3: On the gengxu day of the first month of the third year of the Tianbao reign period, red qi hung from the moon like a sash.

Given the new moons on Jan 19 and Feb 18, the sighting was very close to full moon. The questionable phenomenon is directly related to the moon (and nothing else is reported), so that this sighting could well be a lunar halo display, e.g. a pillar (like a sash, i.e. a bar or belt), red perhaps due to low altitude.

\footnotetext{
${ }^{3}$ In table 5 in Hayakawa et al. (2017b), three of the four aurora candidates with given directions are towards the east-south, so that they are dubious as aurora; one of them (seen for 19 days) is comet C/1618 V1 (Ho Peng Yoke 1962, Kronk 1999). Abbott \& Juhl (2016) also list many events in a southernly direction as aurorae, several of them even during well-known Grand Minima - they are all non-auroral, but some other phenomena like e.g. clouds, halo effects, comets, etc.
} 
761 Dec 13 (not 756 as dated in T+17): During the second night watch on the guisi night of the month jianzi (the eleventh month) in the first year of Suzong (r. 756-762), the moon occulted the Pleiades and was surrounded by a halo, white in color, and there was white qi that came from the north to penetrate it (XTS 32.386).

The 756 date is highly doubtful. There is no guisi [30 in the sexagenary cycle] day in the eleventh month of AD 756, which began on a xinghai day [48 in the sexagenary cycle]. We found two similar reports both suggesting an $\mathrm{AD}$ 761 Dec 13 date. The Xin Tangshu records On the guisi day of the month jianzi in the 3rd year of the Shangyuan reign period, the moon occulted the Pleiades. It emerged to the north of the Pleiades. On the dingmao day of the 8th month, again it occulted the Pleiades (XTS 33.856). Jiu Tang shu 36.1325 reports: In that year (when the reign period name changed to Yuan), on the guisi day of the 11th month, at the hai double hour (21-23h) after the first night drum (in) the 2nd fifth-hour, the moon covered the Pleiades, and then emerged to its north. It was surrounded by a white halo. The stars of Bi (Taurus) had white qi among them which followed the moon north to penetrate the Pleiades. This text is the most detailed among the above variants and also fully consistent as the moon did in fact occult the Pleiades in Taurus that night, see Chapman et al. (2015) for more details on this event.

The confusion likely issues from the dating of the text in the Yuan year of Suzong. Yuan is generally the first year of a reign period; $\mathrm{T}+17$ seem to read it as the first year of the reign of Suzong. However, Yuan is in fact the name of a very brief reign period. During the ninth month of the second year of the Shangyuan reign period, the name of the reign period was changed to Yuan (see Fang \& Fang 1987). The eleventh month was adopted as the beginning of a new year (see XTS 6.164). Hence, while we see the event identified as having occurred both in the Yuan year of Suzong and in the 3rd year of the Shangyuan reign period, these refer to the same actual date. Moreover, the text clearly refers to a halo display rather than an aurora.

767 Aug 17: During the shen double-hour (15h-17h) of the bingyin of the seventh month of the Dali reign period, there was green/blue and crimson (qing and chi) qi more than forty chi in length which appeared on the side of/beside the sun [ri pang]. Only after a long while did it disperse.

Here, the colored qi appeared beside the sun, so that it is clearly some non-auroral atmospheric optical effect. The term ri pang can mean beside the sun or on the side of the sun; see Sect. 4.1.

767 Aug 23: In the seventh month of the second year of the Dali reign period ... On the renshen day of the twelfth month, crimson qi more than two zhang in length stretched across above the sun.

The reddish (crimson) qi was seen stretched across above the sun, so that again it is clearly some non-auroral atmospheric optical effect.
767 Oct 25: On the yihai day of the ninth of the second year of the Dali reign period, green/blue and crimson (qing and chi) qi stretched across on the side of/beside the sun [ri pang].

This is again clearly some non-auroral atmospheric optical effect. We cannot understand as to why $\mathrm{T}+17$ consider this and the previous two events as aurorae; they are clearly related to the Sun. (What is described here as qi ri pang, i.e. vapor on or next to the sun (see Sect. 4.1 for the translation of ri pang), also cannot be interpreted as a sunspot, because it is given as green/blue and crimson and not black.)

829 Sep: In the eighth month (2 Sep-1 Oct) of the third year of the Dahe reign period, in the west there was white qi like a pillar (or like pillars).

White qi like (a) pillar(s) does not fulfil any aurora criterion.

833 Nov 17: On the yiyou day in the tenth month of the Dahe reign period, in the west there again appeared white qi like three pillars.

Again, white qi like pillars does not fulfil any aurora criteria; night-time is again not mentioned. Three pillars could be a halo phenomenon during sunset in the west (light pillars of sun and two mock suns).

893 Nov: In the eleventh month (12 Dec 893-10 Jan 894) of the second year of the Jingfu reign period, there was white qi like a ring that penetrated the moon, went through the Northern Dipper and reached the Grand Tenuity Enclosure / Supreme Subtlety (in Leo and Virgo).

The dating in T+17 to AD 893 Nov is wrong, as the 11th lunar month ran from 12 Dec 893 to 10 Jan 894 . The white qi like a ring that penetrated the moon was obviously a lunar halo ring. Full moon in the given period was AD 893 Dec 26 and indeed, the still almost full moon was in or just south of Leo Dec 28-30, so that its 22 deg halo ring would cross the given constellations.

901 Oct 5: On the yihai day of the eighth month of the first year of the Tianfu reign period, in the west there were white clouds like the soles of shoes, and from among them there issued white qi like a bolt of silk, five zhang in length, upwards it (or 'its top') thrust toward the heavens and separated into three comets [hui], the head dipping downward. It is not mentioned that it happened at night. Five zhang are 50 degrees. Aurora criteria are not fulfilled.

953 May: In third month (16 Apr-15 May) of the third year ... One evening, while in his study at his mountain retreat, there suddenly appeared yellow qi before [the emperor], which rose to reach the heavens. The emperor saw in the yellow qi star patterns, Purple Forbidden (lit. Purple Palace or Purple Tenuity) [circumpolar stars, Chinese: Ziwei] and Wenchang [stars in Ursa Major] appeared brightly before his eyes.

This text is not a real astronomical record. $\mathrm{T}+17$ leave out the lines that follow: He then spoke to the court astrologers saying, 'Isn't it strange to see celestial images while sitting inside my room?' (Chinese text in our Fig. 2). This again shows that it is necessary to consider the context. 
We see that several of the events listed as aurorae (or candidates?) in $\mathrm{T}+17$ are clearly during the day and connected with the Sun, while $\mathrm{T}+17$ wrote in their section 2.2 that they had remove (d) unsuitable ones (e.g. those observed during day-time and so on). In their section 3.1, they write: Lists of aurora candidates are given in tables 1, 2, and 3 ... we found ... 45 aurora candidates (vapor/cloud/light during the night). Their tables 1-3 list 59 candidates. One could consider that the 45 (of the 59) are those where night is mentioned. They give the lunar phase for all events for which they provide an exact date. While the lunar phase is only relevant for events occurring at night, $\mathrm{T}+17$ needlessly include it for those during the day, such as the three events in AD 767 Oct (see our translation above).

While tables 1-3 in $\mathrm{T}+17$ suggest that there were all aurorae, we recommend not to use or plot these tables: among the 11 events just listed, presumable new aurorae from $\mathrm{T}+17$, at most one of them can be considered a likely true aurora (AD 604 Jan 21). Given the many non-auroral phenomena in their list of aurora candidates, it is no surprise that $\mathrm{T}+17$ conclude that it is difficult to see the relation between long-term change of the solar activity and records of aurora and sunspot candidates for 6-10th century (their section 3.6), while Neuhäuser \& Neuhäuser (2015a) after a careful selection of the likely true aurorae could even reconstruct the Schwabe cycle (and more) from the mid 8th to the mid 9th century.

\subsubsection{Sunspot records in Tamazawa et al. (2017)}

We will now consider the sunspots in Tamazawa et al. (2017; $\mathrm{T}+17)$. $\mathrm{T}+17$ reported that they found 16 sunspot candidates (black spots/vapor and unusual ra[i]nbow etc. in the Sun) (their section 3.1); 19 sunspots records, according to their section 3.5, 16 are listed in their table 4. The dearth of Chinese sunspots between AD 579 and 826 was of course well-known since long ago (e.g. Eddy 1976).

All but one of the sunspots in $\mathrm{T}+17$ were listed before, e.g. in Keimatsu (1974), Yau \& Stephenson (1988), or Xu et al. (2000). A comparison between $\mathrm{T}+17$ on the one side and Keimatsu (1974) and Xu et al. (2000) on the other side shows the following differences:

567 Dec 10 in $\mathrm{T}+17$, but Dec 10-18 in Xu et al., 577 Dec in $\mathrm{T}+17$, but Dec 30 in Xu et al.,

579 Apr 3-6 in Xu et al. missing in $\mathrm{T}+17$,

826 May in $\mathrm{T}+17$, but May 24 in Xu et al. (black spot),

829 Jan 20 in Keimatsu (1974), but missing in $\mathrm{T}+17$,

832 Apr (one without day, one on Apr 24) in T+17, but only

Apr 21 in Xu et al.,

837 Dec 22 in $\mathrm{T}+17$, but Dec 22-24 in Xu et al.,

840 Dec 28 in $\mathrm{T}+17$ missing in Xu et al. (see below),

$851 \mathrm{Dec} 2$ in Xu et al. (in Japan) missing in $\mathrm{T}+17$,

$865 \mathrm{Feb}$ (without days) in T+17, but Jan 31 to Feb 28 in Xu et al.,

874 (without day nor month) in T+17, but Jan 22 to Feb 9 in Xu et al.,

875 (without day nor month) in $\mathrm{T}+17$, but $875 \mathrm{Feb} 10$ to
876 Jan 29 in Xu et al.,

925 Dec (without day) in T+17, but Dec 29 in Xu et al., 927 Mar 9 in Xu et al. missing in $\mathrm{T}+17$, and

947 Mar 3 in Xu et al. missing in $\mathrm{T}+17$.

We see again, as in $\mathrm{H}+15$, that the information in previous studies such as $\mathrm{Xu}$ et al. is much more complete. Six sunspot records are missing in $\mathrm{T}+17$; nine have a more precise date in $\mathrm{Xu}$ et al.

$\mathrm{T}+17$ do not mention that all but one of their records were published and translated earlier; nor did they compare the translations. They do not give the English translation for the only new record, namely for AD 840 Dec 28 (table 4 says just $B V$ for black vapor). The original Chinese is shown in our Fig. 2. Our English translation is:

In the fifth year of the Kaicheng reign period ... on the guimao day, the first of the twelfth month [AD 840 Dec 28], there was black qi on the side of the sun [ri pang] that went back and forth jostling about. (On the meaning of ri pang, see Sect. 4.1).

\section{General remarks on terminology}

We will now discuss three general topics from the different publications mentioned, first the meaning of the term $r i$ pang in sunspot and aurora records (4.1), then aurora colors in historical reports (4.2), and finally whether and which rainbows can be interpreted as aurorae (4.3).

\subsection{The meaning of the term ri pang}

We comment here only on the discussion of the term ri pang and a few related issues in Hayakawa et al. (2017b), not on the remaining parts of that publication. Hayakawa et al. (2017b) claim that ri pang can mean only near the Sun. In their appendix I with figure 10, they show three examples where phenomena near the Sun were described with $r i$ pang, possibly halo phenomena. These examples show that ri pang in connection with the Sun can indeed mean near the Sun, beside the Sun, and/or next to the Sun $4^{4}$ Hayakawa et al. (2017b) also acknowledge black spots/vapors near the Sun as potential sunspots, but they did not include those with ri pang in their listing (their appendix I); Tamazawa et al. (2017) interpret the case of AD 840 with ri pang as a sunspot (see Sect. 3.3). Can ri pang - depending on context - realy mean either next to the Sun or on thelone side of the Sun? The term ri pang was translated on the side of the Sun by Wittmann \& Xu (1987), Yau \& Stephenson (1988), and $\mathrm{Xu}$ et al. (2000) in several cases and then included in their sunspot catalogues. Hayakawa et al. (2017b) include Ming shi record MS\#S24 in their list of sunspots (without the term ri pang); however, an analogous report from Shenzong shilu with very similar wording includes ri pang (see

4 Tamazawa et al. (2017) present several cases with this term: green/blue and crimson (qing and chi) qi ... beside the sun (ri pang) (see above for AD 676 Aug 17 and Oct 25 and our Fig. 2), which they include among their aurorae. 
$\mathrm{Xu}$ et al. 2000 for AD 1618 June 20-22). Another record from the Songjiang Fuzhi clearly says for AD 1618 June 22 Within the sun there was a black vapour (Yau \& Stephenson 1988), a typical wording always interpreted as a spot on the disk of the sun. We conclude that ri pang can indeed mean a spot on the sun.

The Chinese naked-eye spot AD 1618 June 20-22 with the wording ri pang is corroborated by Malapert's drawings for June 21-29 (Neuhäuser \& Neuhäuser 2016, their figure 2 ), which is not the only example.

Hayakawa et al. (2017b) comment on this case that Neuhäuser \& Neuhäuser (2016) relate this record [MS\#S24] with ... Malapert during 1618.06.21-29 ... Neuhäuser \& Neuhäuser (2016) interpret the misdated intercalary month of MS\#S24 to intercalary fourth month to speculate this record as on 1618.06.20-22. This interpretation is arbitrary and no more than speculation in a philological view point (their footnote 14). First, we would like to note that it was not Neuhäuser \& Neuhäuser (2016) that suggested to correct the date given as intercalary 6th month in Ming shi and Tianwen zhi to intercalary 4th month, but Wittmann \& Xu (1987), Yau \& Stephenson (1988), and $\mathrm{Xu}$ et al. (2000), as clearly referenced in Neuhäuser \& Neuhäuser (2016, their section 3.2). Then, there are two more reports on this spot: Shenzong shilu clearly gives intercalary 4th month for three days until day wuzi (June 22), see Yau \& Stephenson (1988) and Xu et al. (2000), and Songjiang Fuzhi gives 5th month, 1st day, i.e. June 22 (Yau $\&$ Stephenson 1988). These additional reports clearly support the date correction of the Ming shi and Tianwen zhi records. (Hayakawa et al. (2017b) argue that when two spot records give totally different wordings, they can hardly be regarded as from the same origin (their footnote 14), but we would like to point out that two records can of course be independent from each other, and then confirming each other. Hayakawa et al. (2017b) do not accept the date correction, they also omit the duration of three days in their MS\#S24.)

Furthermore, Hayakawa et al. (2017b) argue that the date wuzi does not exist in the intercalary 4th month of this year (their footnote 14), but the Chinese sources did not specify that day wuzi would be in the intercalary 4th month. They instead say: ... from intercalary 4th month day bingxu (June 20). For three days until day wuzi ... (June 22) in Shenzong shilu and year wuwu (46th), 5th month, 1st day... (June 22) in Songjiang Fuzhi, day wuzi is the 1st day of the 5th month, and the spot was seen from the 2nd-to-last day in the intercalary 4th month to the 1st day in the 5th month. In their translation of sunspot MS\#S24, Hayakawa et al. (2017b) leave out the wording From day bingxu (23) until day wuzi (25), as given in Xu et al. (2000) from Ming shi, Tianwen zhi, san chap. 27. This example again shows how important it is to include all records available (including local and inofficial ones), and not limiting a study to those available in electronic form (as done by $\mathrm{H}+15, \mathrm{H}+16, \mathrm{~K}+16, \mathrm{~T}+17$, and Hayakawa et al. 2017b). They ignore the critical philological and historical work by previous scholars, e.g. regarding date corrections (see appendix I in Hayakawa et al. 2017b). While Abbott \& Juhl (2016) dated the 1618 June 20-22 spot as, e.g., Xu et al. (2000), they gave intrinsically inconsistent translations: for the one on 1618 June 20 though 22 from Mingshi Tianwen, they translate ri pang as On one side of the Sun, while in an additional record for 1618 June 22, they translate qi ri pang as vapor next to the sun; the latter record given in Abbott \& Juhl (2016) includes intrinsically that a spot was seen also June 20 and 21. An extra sentence given in the translation of Abbott \& Juhl (2016) about the observation on June 22 clearly shows that this was not something outside or next to the disk of the sun (like a mock sun), but on the disk of the sun i.e. a sunspot: On the 22nd [June], at 1-3 pm, I used a bowl of water at home to observe the sun and saw a black vapor next to the sun [ri pang] (the correct translation here would have to be ... black vapor/qi on the/one side of the Sun) - such a bowl of water as observing tool would not be needed for some black cloud next to the sun, but only for some feature on the disk of the sun. With the wording next to the sun, one could possibly also mean before the sun, e.g. as a shadow of a transiting small body, a theory also discussed in Europe that time. The sunspot catalogue of Abbott \& Juhl (2016) contains only some 15 new records, all others were given by one to several previous publications by others (mostly not cited by Abbott \& Juhl 2016), and they missed several East Asian sunspots listed by others 5

\footnotetext{
${ }^{5}$ Hayakawa et al. (2017b) write We found a probable coincidence between Chinese sunspot records and western sunspot drawings in $1618.06 / 07$, i.e. MS\#S22 and MS\#S23 and sunspot drawings by Malapert (1633) as shown in Fig. 6 ... Although the sunspot size is intriguing, Malapert (1633) seems not to draw shapes of sunspots but to place dots where sunspots locate (their section 4). It is not clear which coincidence they mean: they date sunspot MS\#S22 to AD 1618 May/June and date their sunspot MS\#S23 to AD 1618 June/July. In the above quoted statement they wrote western sunspot drawings in 1618.06/07 (i.e. without May); their drawing in figure 6 mentions sunspots in June and July in the caption, but shows sunspots from July only in the figure parts. While Hayakawa et al. (2017b) claim to have found a coincidence between some Chinese nakedeye sunspots in AD 1618 May/June/July with some telescopic drawings, we would like to note that the coincidence of the Chinese sunspot records of AD 1618 June 20-22 and the drawings by Malapert for AD 1618 June 21-29 were first noticed in Neuhäuser \& Neuhäuser (2016), who wrote about this spot: We estimated the spot size to be about 1600 square arc sec, so that the spot would not be visible to the naked eye (...); we conclude that Malapert did not draw the spot size to scale here: note that all spots in this drawing are very similar, which is not typical - since Malapert supported the transit theory, his main interest may have been the path of the spot( $(s)$, shown with correct curvature (B angle) in his drawings ... (caption to their figure 2, which shows the sunspot drawing by Malapert (1633) for 1618 June 21-29). Both dates in footnote 21 of Hayakawa et al. (2017b) on sunspot MS\#S24 are wrong. Their statement that no Western Calendar dates can be given for the 4th intercalary month (their footnote 21) is also wrong: the date range for that month is AD 1618 May 24 to June 21, as e.g. given in their footnote 19 . Also the claim by Hayakawa et al. (2017b) that Neuhäuser \& Neuhäuser (2016) related this record [MS\#S24] with the left drawing of [their] Figure 6 by Malapert during 1618.06.21-29 is not correct. Figure 6 of Hayakawa et al. (2017b) does not show the sunspots AD 1618 June 21-29 and July 7-19 as they claim in their caption (figure 6), but the left hand-side of their figure 6 shows the sunspot AD 1618 July $7,9,13-15,17$, and 18 (as observed by Malapert) and the right hand-side figure shows the spot seen AD 1618 July 8, 13, 18, and 19 as observed by Simon Perovius SJ from Kalisz in Poland - with dates, observers, and
} 
The sunspot of AD 1618 June/July (MS\#S23 in Hayakawa et al. 2017b), which they date to sometime from June 22 to July 21 (their footnote 20), is almost certainly the spot(s) dated to June 22 by Yau \& Stephenson (1988), would then not be simultaneous with the aurora on AD 1618 July 19 as claimed by Hayakawa et al. (2017b, their last section); instead, that aurora is simultaneous with the telescopic sunspot(s) of Malapert and/or Perovius AD 1618 July 7-19 (table 6 in Neuhäuser \& Neuhäuser 2016), also seen in figure 6 of Hayakawa et al. (2017b), which has an inaccurate caption. It is therefore also not justified to conclude that MS\#S23, which they cannot date well, caused a flare and brought a magnetic storm with low latitude aurora on 1618 July 19 and scientifically detected as a nitrate signal in 1619, as Hayakawa et al. (2017b) claim.

\subsection{Aurora color (e.g. Hayakawa et al. 2015, 2016)}

In their example quotation (a) for aurorae, listed in their section on auroral records, $\mathrm{H}+15$ present an event as palewhite, while it is given as B[lue-]W[hite] in their table 2; this was B[lue-]W[hite] in Keimatsu (1974), green-white in Yau et al. (1995), and greenish-white in Xu et al. (2000).

$\mathrm{H}+15$ should have discussed the differences in the translations. Instead, H+15 consider the colors of wuxing (five elements) given by them in their section on auroral records as white, red, green, yellow, and black, while in their section on color of aurora, the colors of wuxing are given as white, red, blue, yellow, and black. $\mathrm{H}+15$ do not mention that the color qing is sometimes rendered as blue, sometimes as green.

Also, their sentences there are more white auroras than the red auroras and there are more red auroras than white (green) auroras appear to be in contradiction (both in their section on color of aurora). $\mathrm{H}+15$ understand green aurorae to be represented with the color bai, conventionally translated as white, whereas the color qing is conventionally translated as blue or green. It may not be justified to consider events reported as white (e.g. white qi) to be green aurorae, as $\mathrm{H}+15$ did. These events may not be aurorae at all.

$\mathrm{H}+16$ suggested that white rainbows could be aurora candidates (see next Sect. 4.3). Because white would not be typical for aurorae, they try to explain, why this word can appear in an aurora: When observing a very faint aurora, ... the color can be recognized as whitish because the target is not bright enough (their section 4.1). T+17 make a similar claim: If the red aurora ... occupied the background, one would see the aurora as white (their section 3.2). Because auroras are not really 'white' $(\mathrm{H}+16), \mathrm{H}+16$ conclude that the observers in fact meant green or yellow: it is reasonable to assume that green or faint yellow auroras were expressed as white as they do not have 'green' as a base color in their traditional concept $(\mathrm{H}+16)$. What if the court astronomer

locations given are in the drawing and Malapert's caption (partly also seen in the scan published by Hayakawa et al. 2017b) as well as in Neuhäuser \& Neuhäuser (2016). really meant white being one of their wuxing colors? The color green is between the wuxing colors yellow and blue (if we read qing as blue rather than green), and there is some green tending to yellow and some green tending to blue, so that yellow and blue would appear as more natural proxies for green.

Real green aurorae appear normally at low height; to observe them at low geo-magnetic latitude such as China, one would need strong solar storms. When $\mathrm{H}+15, \mathrm{H}+16$, and $\mathrm{T}+17$ (e.g. $\mathrm{T}+17$ think that at least some of the white aurora candidates were indeed the green (white) auroras, their section 3.2) they convert records of a white phenomenon to a green aurora, i.e. to a strong storm. In doing so, they in fact modify the sources, thereby overestimating solar activity.

Their table $2(\mathrm{H}+15)$ includes many cases, where something $R[e d]$ is reported at sunset in the west (15 cases), which are almost certainly real sunsets with glow, and also cases, where something $R[e d]$ is reported at sunrise in the east (six cases), which are almost certainly real sunrises hence, a real aurora but not an aurora borealis (northern light). Previous aurora borealis catalogues did not include such events. Even though the Chinese documents of course do not include all red sunsets nor all red sunrises, it is not justified to include them as aurora borealis or even as candidates, because they could just have been exceptionally red sunrises or sunsets due to, e.g., very high humidity, smoky conditions, or dust storms.

Aurora colors were recently also discussed in Abbott \& Juhl (2016), namely as presumable indicator for the amount of ${ }^{14} C$ production: we postulate that the most energetic (e.g. luminous) auroras will have a white component ... The other colors of auroras: yellow, dark blue, violet, purple, and light blue ... are more likely to represent auroral excitation during higher energy events (their section 2.3); this may appear contradictory. They also considered so-called black aurorae: Black auroras are dark areas of aurora-like activity within a surrounding aurora ... The origins of black auroras are not fully understood (Abbott \& Juhl 2016, their section 2.3). However, if something reported as black (e.g. black qi/vapor) could be considered as aurora, then one would definitely have to expect that aurora of some other (real) color would also be reported, such as red qi; if no other colors are reported, than the interpretation of something black as aurora is highly dubious. This problem affects many presumable aurorae in Abbott \& Juhl (2016).

\subsection{White and unusual rainbow (Hayakawa et al. 2016)}

In $\mathrm{H}+16$, it is suggested to interpret white rainbows (bai ni) and unusual rainbows (hong ni) as aurorae. While $\mathrm{H}+16$ point to the fact that in most cases, the white rainbow is reported to pierce the Sun or the moon (their section 3), which they consider as solar/lunar halos or similar atmospheric optics phenomenal (their section 3). Obviously, this is the halo phenomenon called horizontal arc, which is white; as an arc (or bow), it can pierce the Sun or moon. $\mathrm{H}+16$ found 
eleven cases of white rainbow and two cases of unusual rainbow, without mention of Sun or moon, including 3 reports in the Jin tang shu and ten cases in the Xin tang shu, the two official chronicles of the Tang dynasty (AD 618907).

Other white rainbows (bai ni), not mentioned to pierce the Sun or moon, are listed under a section heading called unusual rainbow (hong ni) in the omenology treatise wuxing of the Xin tang shu. These are probably some other phenomena, i.e. not horizontal arcs through Sun or moon. The term hong ni (translated as unusual rainbows in $\mathrm{H}+16$ ) is a binome composed of two different single-syllable words both meaning rainbow. $\mathrm{Ni}$, or $\mathrm{ci} \mathrm{ni}$, sometimes refers to a fainter, secondary rainbow ${ }^{6}$ However, it is not justified to consider those phenomena as different from the atmospheric optics events of solar or lunar origin and instead to consider them as aurorae $(\mathrm{H}+16$, their section 4.1). $\mathrm{H}+16$ neglect the large variety of other somewhat significant rainbows, which were to be reported and later compiled, e.g. fog bows, sometimes also called white rainbows, double and abnormal rainbows, horizontal arcs away from Sun or moon, and other halo arcs, see Minnaert (1993). Such bows and arcs were also called rainbows in European sources until the Early Modern Pe$\operatorname{rioc}^{7}$ and they all, whether day or night, are related to Sun or moon due to reflection or refraction. The statement by $\mathrm{H}+16$ that auroras appear at night, and the usual rainbows appear during the day-time (their section 3 ) is misleading.

At least seven of the eleven white rainbows (listed in $\mathrm{H}+16$ ) were observed westwards (laying across westwards or similar). A white bow in the west does not fulfil any of the aurora criteria from Neuhäuser \& Neuhäuser (2015a). Only in two of those cases, it was reported that it happened at night, namely JT 2 and XT 10. (H+16 claim (at the end of their section 3 after the translations) that XT 10 would give night, but that it is not given in their translation; however, the word night is indeed there in the Chinese text.) Observations of phenomena which are described in similar form for day- and night-time, are not good candidates for rare auroral displays which can be detected only at night.

In XT 5, a white rainbow is reported to lay across east to west $(\mathrm{H}+16)$, not atypical for aurorae. It is not justified

\footnotetext{
6 Chapman et al. (2015) wrote: There are several different words conventionally translated as rainbow in classical Chinese. Daidong appears in the Classic of Poetry, while both ni and hong appear in astronomic and omenological texts, where they are largely used synonymously. A distinction is sometimes drawn in the genders of the ni and the hong; the term ni often occurs in the phrase ci ni, a female rainbow. Unlike the English word rainbow, hong is composed of a single element, not two independently meaningful morphemes, rain and bow.

7 In medieval to late renaissance European texts, the word usually translated as rainbow often stands for an arc or bow from a halo display (Neuhäuser \& Neuhäuser 2015d); in antiquity, arcus pluvius was used for rain bow in today's sense, arcus imbrifer for rain bringing arc (probably the $22^{\circ}$ halo ring), and arcus caelestis for arc on sky (probably some particular halo bow); hence, there is a clear possibility to differentiate between different bows, e.g. a real rainbow in the current modern sense which happens after a rain around the anti-solar point or a halo arc or bow around the Sun called a rain bringing arc, which is connected to the ancient wisdom that halo rings (or bows) are often followed by rain, an incoming depression (e.g. in Meteorology by Aristotle), see also Minnaert (1993).
}

to conclude that the description filled up the heaven would mean to be spreading across the sky through the region around the zenith and likely to imply aurora, as done by $\mathrm{H}+16$, given that they neither know what kind of white rainbow is meant nor what the given size of as wide as 5 chi means (see also the end of their section 3); 5 chi are some 5 degrees, consistent with the width of a fog bow (Minnaert 1993). JT 3 and XT 2 have the wording an unusual rainbow filled up the heaven/sky. Again, a phenomenon called rainbow, a somewhat narrow band, cannot really fill up the whole sky as implied by $\mathrm{H}+16$, but one could use this wording to mean something crossing large areas of the sky with a large angular extend, e.g. all sorts of bows mentioned above. All three reports (JT 3, XT 2, XT 5) do not mention nighttime. In both XT 2 and example (a) given in section 4.2 in $\mathrm{H}+16$ (AD 1363 July 30: two white rainbows, which directly hit the Plough), $\mathrm{H}+16$ incorrectly translated the Chinese Beidou to Plough, one should use Northern Dipper or Big Dipper, the constellation referred to here.

According to two more records, a white rainbow descended into the city (XT 1) and descended to the gate of their camp (XT 3), so that these phenomena seem to have been observed nearby and low; the impression of closeness is atypical for aurorae, but often reported for halo displays as well as fogbows and rainbows. As these two events coincide with military events (normally at day-time) in the locations where they occur, the records should be regarded as somewhat suspect.

$\mathrm{Xu}$ et al. (2000), the most recent critical compilation of East Asian aurorae for the last two millennia, excludes all records which do not explicitly report night-time. The claim by $\mathrm{H}+16$ that there are no explicit records of day-time observations of 'white rainbows' or 'unusual rainbows' in our list is again strongly misleading. Obviously, the professional Chinese court astronomers did not explicitly specify whether something was at day- or night-time, when it was during the day-time - there may well be a few rare exceptions (e.g. SN 1054). Therefore, when $\mathrm{H}+16$ imply a lack of information regarding day- or night-time, they oversee that the information is implicitly given.

The listing in $\mathrm{H}+16$ includes only one case mentioning more than one band, namely XT 4, the four white rainbows ... observed at night on AD 757 Feb 20. While it may in principle be possible to observe several atmospheric optics arcs or bows at night at once (moon-related), this observation was close to new moon, which is the main argument for considering it seriously as aurora candidate. Among all the 13 white rainbows or so-called unusual rainbows presented in $\mathrm{H}+16$, only the one in AD 757 (XT 4) could be auroral, as considered by others ${ }^{8}$

\footnotetext{
$8 \mathrm{H}+16$ wrote that previously, white rainbow was not considered to be an aurora and that Chapman et al. (2015) also mentioned a possibility that white rainbow in 757 could perhaps be an aurora $(\mathrm{H}+16$, their section 1). Chapman et al. (2015) in fact considered the report about four white rainbows in $\mathrm{AD} 757$ in their section on questionable aurora reports and wrote that this event was listed as an aurora in Keimatsu (1973) ("probable to doubtful"), Yau et al. (1995), and Xu et al. (2000).
} 
Then, $\mathrm{T}+17$ also include several cases of rainbow in their list of (presumable) aurorae, all or most of which may well be some atmospheric optical phenomena (see our Sect. 3.3.1). Given that aurora colors and forms might in some historical cases have been compared to rainbows (e.g. like a rainbow), Carrasco et al. (2017) also searched for such reports; since such reports would always remain somewhat dubious, they can never be strong aurora candidates 9

\section{Conclusion}

We have critically reviewed the articles by Hayakawa et al. (2015, 2016, 2017ab), Kawamura et al. (2016), and Tamazawa et al. (2017), where they searched electronically for certain words presumably referring to aurorae and sunspots. Apart from internal inconsistencies within the papers, unclear or missing criteria, translation errors, omission of relevant details, and the fact that they do not cite most of the other articles which presented their likely true spots and aurorae before $\sqrt{10}$ there are strong shortcomings in the digital

\footnotetext{
9 The three unusual rainbows presented in Carrasco et al. (2017) as possibly auroral could also be other phenomena: in particular their 2nd case, seen in Rio, Brazil, where a reknowned scientific scholar (Sanches Dorta) reports a rainbow produced by refraction of the rays of the moon ... bases on the WSW and ESE ... very white, one should consider an arc of the white horizontal lunar halo circle - halo bows were often called rainbow in former times (see previous footnote) - here seen in the evening $(6 \mathrm{~h} 10 \mathrm{~m}$ to $7 \mathrm{~h} 18 \mathrm{~m}$ ) formed by the moon moving from the $\mathrm{N}$ to the $\mathrm{W}$, due to ice crystals from an incoming depression (later white cloud in the $\mathrm{S}$ and lighting in the ESE), at least high humidity (whole atmosphere was slightly reddish). Although some aurora criteria seem to be fulfilled, the whole report is more consistent with something else (see introduction to this paper and as already stressed in Neuhäuser \& Neuhäuser 2015a); the horizontal halo arc can be seen up to 360 degrees all around the horizon, or in parts (arcs/bows), and it can change in extend and intensity according to weather conditions and illumination; if this event would have been an aurora, seen at the very low latitude of Rio, it would have been a very strong solar storm, but there are only few other reports those days (at mid-latitude only). Their 3rd case was a perfect rainbow ... like ashy at full moon around the time of a small storm, seen for a few minutes in the north, which could well be a fogbow or lunar rainbow (see Minnaert 1993). Only their first case is during the dark night, i.e. without the moon, a feature between $\mathrm{N}$ and $\mathrm{W}$, which changes its shape, described as fire swords ... band or circle of fire as a rainbow. This could be an aurora.

10 This is similar to the study of Hayakawa et al. $(2017 \mathrm{c})$, and we otherwise do not examine it. The only sunspot presented (7th-9th century Japan) was already known: Hayakawa et al. (2017c) refer to this record as an instance of hei dian as a black spot, while both Wittmann \& Xu (1988) and Xu et al. (2000) translate it as black dot. Hayakawa et al. (2017c) then list 13 presumable aurorae. With one exception, these either have been published previously or refer to non-auroral phenomena, including several instances that occur during the day or near the full moon; their figure 4 with one or two presumable aurorae per lunar phase bin is all but meaningless. In detail, the 13 presumable aurorae have the following issues: (i) The sightings for 20 Dec 620 (their A1) and (ii) 18 Sep 682 (A2) were listed in Yau et al. and Keimatsu et al., respectively. (iii) The aurora dated by Hayakawa et al. (2017c) as A3: 08 Oct 839 ... Translation: On $10 \mathrm{Au}$ gust 839 ... was dated AD 839 Aug 10 in, e.g., Yau et al. (1995) and Xu et al. (2000), where the translation is also significantly different. (iv) The presumable aurora listed as A4: 27 July 847 ... a white vapor emerged out of the lunar halo and surrounded it was not given in any other aurora catalog before, because it was a lunar halo phenomenon a few days before full moon. (v) The presumable aurora listed as A5:05 Nov 857 ... during the day, a white cloud appeared ... from the east to west was not given in
}

method as applied by these authors, e.g. they missed a number of entries found in other catalogues based on the same primary sources. Several of these publications present most of the Chinese texts only on a web page, without English translations. They ignore critical philological and historical work by scholars, e.g. regarding corrections of dates due to mistakes by copying scribes (and, e.g., the meaning of ri pang, see our Sect. 4.1). Their arguments are sometimes misleading (e.g. regarding aurora colors, see our Sect. 4.2). They make unjustified assumptions, e.g. that observations without explicit mention of day- or night-time, would be at night (our Sect. 4.3). The previously mentioned recent publications restricted the search to official Chinese dynasty reports, which limits the resulting completeness, as there were also reports on celestial phenomena in local gazetteers etc.

Many presumable new aurorae (and sunspots) were previously (and rightfully) rejected by others, because they are much more likely other celestial or atmospheric events ${ }^{11}$ like particularly red sunrises and sunsets or well-known comets; many of the white and unusual rainbows could easily be fog bows or other atmospheric optical phenom-

any other aurora catalog before, because it was not during night-time. (vi) The presumable aurora listed as A6: 24 July 858 ... early in the morning, a white cloud extended from $N W$ to $S W$... was not given in any other aurora catalog before, because it was not during dark night. (vii) 13 Nov 859 (A7) also in Yau et al. (1995). (viii) The presumable aurora listed as A8: 09 Nov 864 ... during the night, a light appeared on the northern mountains and was as intense as lightning. Red light was also observed in front of the Suzaku Gate ... was not given in any other aurora catalog before; among the two phenonema reported, the first is given with terms atypical for aurorae, it is not explicitely reported to be on sky, our literal translation of the Japanese text is As for the northern mountain(s), there was light; in the second, Suzaku Gate is the Japanese pronounciation for Zhu Que for Crimson Sparrow, it may refer to a set of seven lunar lodges ranging from Well (in Gemini) to Axletree (in Corvus), during this night, the area from Gemini to Corvus rose roughly in the East, while the moon was far away setting in the West; alltogether, it could have been an aurora; this context should have been discussed in detail by Hayakawa et al. (2017c). (ix) The presumable aurora listed as A9: 17 July 865 ... around dawn, the color of the moon was purely yellow. There was a red cloud covering it was not given in any other aurora catalog before, because it was not at night. (x) The presumable aurora listed as A10: 28 Aug 876 ... at dusk ... was not given in any other aurora catalog before, because it was not at night. (xi) The presumable aurora listed as A11: 16 Oct 876 ... a white cloud appeared in the southern heavens, extending across from the $E$ to $W$ was not given in any other aurora catalog before, because it was an extended white cloud in the south, close in time to full moon. (xii) The presumable aurora listed as A12: 20 Apr 883 ... at twilight, a lunar halo came ... a white vapor emerged from the north and entered into the halo ... was not given in any other aurora catalog before, because it was a lunar halo effect a few days before full moon. (xiii) The presumable aurora listed as A13: 14 Aug 885 ... a blue cloud appeared in the heavens, extending from the NE to $S W$ was not given in any other aurora catalog before - night-time is not mentioned and a partly southern direction and purely blue color (without red) would also be dubious for an aurora.

11 This is indirectly confirmed by Kataoka et al. (2017), who investigated presumable aurora candidates in $\mathrm{H}+15$ and $\mathrm{T}+17$, which happened within 10 days, i.e. a small subset, they wrote: We investigated the occurence pattern ... of historical auroras by Tamazawa et al. (2017) and Hayakawa et al. (2015). Their terms in oriental historical documents are known as "vapor", "cloud", "light", etc. ... a detailed visual inspection of the records was conducted to eliminate meteorological phenomena, such as sundog-like events (their section 3). This means that halo (and other non-auroral) effects are still listed among the presumable aurorae in $\mathrm{H}+15$ and $\mathrm{T}+17$. 
ena like in particular halo phenomena. $\mathrm{H}+15, \mathrm{H}+16, \mathrm{~K}+16$, Hayakawa et al. (2017ab), and $\mathrm{T}+17$ do not discuss such differences in classification compared to previous publications. In their event tables (partly inconsistent with their figures, partly with wrong datings, and including some duplications), they present only a few abbreviated keywords from the texts, they do not indicate whether night-time was specified for presumable aurorae (but they give lunar phases also for day-time observations which mention the sun), so that the reader cannot consider, whether alternative interpretations are more probable. We therefore cannot recommend their lists for solar activity reconstructions. Moreover, among eleven presumable new aurorae from Tamazawa et al. (2017), for which we present the original Chinese and a first English translation, at most one of them might be a true aurora; some others being halo phenomena (partly mentioned to be located beside the sun). There have also been other cases in which halo effects were misinterpreted ${ }^{12}$

We therefore recommend great care when applying the automatic search technique to digitally available data bases to find certain phenomena. To study solar activity, one does

\footnotetext{
12 (i) Zolotova \& Ponyavin (2016) recently suggested an event in the deep part of the Maunder Minimum to be an aurora, which was found to be a halo display by Usoskin et al. (2017). (ii) Usoskin et al. (2013) considered three events in the mid 770ies as aurorae (two of them also listed in Link 1962), which were in fact halo displays (Neuhäuser \& Neuhäuser 2015b). (iii) Allen (2012) performed a quick Google search and presented a red crucifix after sunset in the Anglo-Saxon Chronicle, presumably ob-

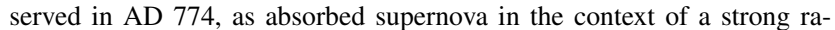
diocarbon variation around $\mathrm{AD} 775$ (suggested as aurora by, e.g., Usoskin et al. 2013); however, neither Allen (2012) nor Usoskin et al. (2013) took into account that critical editions by scholars of Anglo-Saxon history date this entry to AD 776 (e.g. Whitelock 1979), nor that it was classified (and dated) correctly as a halo display (in AD 776) by Newton (1972). This red cross received much scholarly and public attention and was misinterpreted also as airglow etc.; see Neuhäuser \& Neuhäuser (2015b) for a detailed discussion. (iv) Abbott \& Juhl (2016) list $\sim 150$ entries in their aurora catalogue only from AD 1523 to 1566 , which includes the Spörer Minimum. All these records are from Korea, where (like in other East Asian countries) both weather and astronomical phenomena are recorded together. Most of these presumable aurorae are either white only or black only, so that they could easily be non-auroral meteorological phenomena like halos, often even named explicitely as such, and some are comets (see, e.g. footnote 2). E.g., for AD 1526 Mar 22, they give: Night. The moon haloed and there was a white vapor passing through it transversely (only 5 days before full moon). Also, if there is a halo during the day and then some white or black vapor during the next night, which does not fulfil any more aurora criteria (than night-time), then it can very easily be a lunar halo effect, given a similar weather pattern during day and night, namely an incoming depression (sometimes thunder and lightning are also mentioned). Abbott \& Juhl (2016) specify some terms (to be found in their aurora catalogue) in their appendix A for table A4: (2) Embracement (semi-circles / found by the side of and concave towards the sun, and (4) Opposition (a bluishwhite and red vapor shaped like the new moon but convex towards the sun, which are obviously both observed during the day, i.e. non-auroral, but certain halo effects; and (3) Hong (daytime: parhelic circle/arc, nighttime: arc), but there is no reason to assume that hong cannot mean a lunar halo effect. In their aurora table to start at AD 500 (supplementary material), they also include the red cross in $\mathrm{AD} 774$ and the two burning shields in AD 776, which are both non-auroral (Neuhäuser \& Neuhäuser 2015bd). Given that very many non-auroral phenomena are included in their aurora catalogue, all the statistics and conclusions on aurora color distribution in Abbott \& Juhl (2016) are unjustified, and it is not a surprise that Abbott \& Juhl (2016) have to conclude: The results for blue and violet/purple auroras are inconsistent with their known physics (their section 5).
}

not need as many aurorae or sunspots as possible, but credible ones. Electronic searches are a valuable tool. Yet they should always be applied to the full relevant corpus and be employed in conjunction with previous scholarship. Moreover, to understand historical reports, a critical historical exegesis has to be applied considering context, terminology, and dating. Any such search must by unbiased and openminded for celestial signs other than sunspots and aurorae, namely considering the vast variety of astronomical and meteorological phenomena.

Acknowledgements. We obtained data on lunar phases from Rita Gautschy at www.gautschy.ch/ rita/archast/mond/Babylonerste.txt (Gautschy 2014). We would like to thank Daniela Luge (U Jena) for help with the translation of the Latin text from Odericus Vitalis.

\section{References}

Abbott, D. \& Juhl, R., 2016, AdSpR 58, 2181

Allen, J., 2012, Nat 486, 473

Basurah, H.M., 2005, SoPh 225, 209

Basurah, H.M., 2006, J. Atm. Physics and Solar-Terr. Physics 68, 937

Carrasco, V.M.S., Trigo, R.M., Vaquero, J.M., 2017, PASJ in press, arXiv:1705.06773

Chapman, J., Neuhäuser, D L., Neuhäuser, R., Csikszentmihalyi, M., 2015, AN 336, 530

Clarke, D.H. \& Stephenson, S.R., 1978, QJRAS 19, 387

Cook, D., 2000, Revue des mondes musulmans et de la Mediterranee 91-94, 29

Dall’Olmo, U., 1979, J. Geophys. Res. 84, 1525

Eddy, J.A., 1976, Sci 192, 1189

Fang, S.M. \& Fang X.F., 1987, Zhongguo shi liri he Zhong-Xi liri, Shanghai cishu

Fritz, H., 1873, Verzeichnis beobachteter Polarlichter, Verlag C. Gerold's Sohn Wien

Gautschy, R., 2014, JHA 45, 79

Goldstein, B.R., 1965, AJ 70, 105

Hayakawa, H. Tamazawa, H., Kawamura, A.D., Isobe, H., 2015, EP\&S 67, $82(\mathrm{H}+15)$

Hayakawa, H. Isobe, H., Kawamura, A.D., Tamazawa, H., Miyahara, H., Kataoka, R., 2016, PASJ 68, 33 (H+16)

Hayakawa, H. Tamazawa, H., Uchiyama, Y., et al., 2017a, Solar Physics 292, 12

Hayakawa, H., Tamazawa, H., Ebihara, Y., Miyahara, H., Kawamura, A.D., Aoyanna, T., Isobe, H., 2017b, PASJ, in press, arXiv: 1705.02238

Hayakawa, H., Iwahashi, K., Tamazawa, H., Ebihara, Y., Kawamura, A.D., Isobe, H., Namiki K., Shibata K., 2017c, PASJ, in press, arXiv: 1708.01045

Hetherington, B., 1996, A chronicle of pre-telescopic astronomy, Wiley

Hirayama, S., 1889, Observatory 12, 217

Ho Peng Yoke, 1962, Vistas 5, 172

Jeremiah, J., 1870, Nat 3, 174

Kataoka, R., Isobe, H., Hayakawa, H., et al., 2017, Space Weather 15,392

Kawamura, A.D., Hayakawa, H., Tamazawa, H., Miyahara, H., Isobe, H., 2016, PASJ 68, $79(\mathrm{~K}+16)$

Keimatsu, M., 1970, A chronology of aurorae and sunspots in China, Korea, and Japan, Part I (centuries BC), Ann. Sci. Kanazawa Univ. Report 7, 1-10 
Keimatsu, M., 1971, A chronology of aurorae and sunspots in China, Korea, and Japan, Part II (AD 1-3 century), Ann. Sci. Kanazawa Univ. Report

Keimatsu, M., 1972, A chronology of aurorae and sunspots in China, Korea, and Japan, Part IV (AD 4-5 century), Ann. Sci. Kanazawa Univ. Report

Keimatsu, M., 1973, A chronology of aurorae and sunspots in China, Korea, and Japan, Part IV (AD 6-8 century), Ann. Sci. Kanazawa Univ. Report 10, 1-32

Keimatsu, M., 1974, A chronology of aurorae and sunspots in China, Korea, and Japan, Part V (AD 800-1000), Ann. Sci. Kanazawa Univ. Report 11, 1-36

Keimatsu, M., 1975, A chronology of aurorae and sunspots in China, Korea, and Japan, Part IV (AD 1001-1130), Ann. Sci. Kanazawa Univ. Report 10, 1-32

Keimatsu, M., 1976, A chronology of aurorae and sunspots in China, Korea, and Japan, Part VII (Brief Summary), Ann. Sci. Kanazawa Univ. Report 13, 1-32

Krivsky, L. \& Pejml, K., 1988, Publ. Astron. Inst. Czech Acad. Sci. 75,32

Kronk, G.W., 1999, Cometography Vol. 1, Cambridge Univ. Press, Cambridge, UK

Lee, E.H., Ahn, Y.S., Yang, H.J., Chen, K.Y., 2004, SoPh 224, 373

Link, F., 1962, Geofysikalni Sbornik 10, 297

Mairan de, J.J., 1733, Traite physique et historique de l'aurore boreale, De L'Imprimerie Royale Paris

Matsushita, S., 1956, J. Geophys. Res. 61, 297

Mekhaldi, F., Muscheler, R.; Adolphi, F., et al., 2015, Nat. Com. 6,8611

Minnaert, M.G.J., 1993, Light and color in the outdoors, Springer New York (based on original Dutch edition from 1974)

Miyake, F., Nagaya, K., Masuda, K., Nakamura, T., 2012, Nat 486, 240

Miyake, F., Masuda, K., Nakamura, T., 2013, Nat Com DOI:10.1038/ncomms2783

Neuhäuser, R. \& Neuhäuser, D L., 2015a, AN 336, 225

Neuhäuser, D.L. \& Neuhäuser, R., 2015b, AN 336, 913

Neuhäuser, R. \& Neuhäuser, D L., 2015c, AN 336, 930

Neuhäuser, D.L. \& Neuhäuser, R., 2015d, Himmelspredigt: HaloErscheinungen in der Reformationszeit. in: Salatowsky, S. \& Lotze, K.H. (Eds.) Katalog zur Ausstellung "Himmelsspektakel. Astronomie im Protestantismus der Frhen Neuzeit", Verffentlichungen der Forschungsbibliothek Gotha, Vol. 52, Gotha 2015, 12-23

Neuhäuser, R. \& Neuhäuser, D.L., 2016, AN 337, 581

Neuhäuser, R., Rada, W., Kunitzsch, P., Neuhäuser, D L., 2016, JHA 47, 359

Neuhäuser, R., Neuhäuser, D L., Rada, W., Chapman, J., Luge, D., Kunitzsch, P., 2017, AN 338, 8 (arXiv:1607.02915)

Newton, R.R., 1972, Medieval chronicles and the rotation of the Earth, John Hopkins Univ. Press, Baltimore and London

Rada, W.S. \& el-Najeh, S.M., 1997, Astrophysical properties of solar aurora from medieval Arabic and Islamic sources, from 785-1870 AD, in: Proc. of 2nd Arab Astronomical Conf.

Rethly, A. \& Berkes, Z., 1963, Nordlichtbeobachtungen in Ungarn (1523-1960), Verlag der Ungarischen Akademie der Wissenschaften, Budapest

Schöning, G., 1760, Nordlysets, in: Kibeiihuvis laerde Selskabs Skrifter, Theil 8, 197-316

Schove, D.J., 1955, J. Geophys. Res. 60, 127

Schove, D.J., 1964, GeoRu 54, 448

Schove, D.J., 1984, Chronology of eclipses and comets AD 11000 , St. Edmundsburry Suffulk
Silverman, S., 1998, JASTP 60, 997 (spdf.sci.gsfc.nasa.gov)

Stephenson, F.R., 2015, Adv. Sp. Res. 55, 1537

Stephenson, S.R. \& Green, D.A., 2002, Historical supernovae and their remnants, Claredon press Oxford

Stothers, R., 1979, ISIS 70, 85

Strom, R., 2015, Some statistical aspects of historical Chinese astronomy records, in: Orchiston, W., Green, D.A., Strom S. (Eds.) New insights from recent studies in historical astronomy: following in the footsteps of F. Richard Stephenson, Springer, pp 191-204

Tamazawa, H., Kawamura, A.D., Hayakawa, H., Tsukamoto, A., Isobe, H., Ebihara, Y., 2017, PASJ 69, 22-1 (T+17)

Usoskin, I.G., Kromer, B., Ludlow, F., Beer, J., Friedrich, M., Kovaltsov, G.A., Solanki, S.K., Wacker, L., 2013, A\&A 552, L3

Usoskin, I.G., Kovaltsov, G.A., Mishina, L.N., Sokoloff, D.D., Vaquero, J., 2017, SoPh 292, 15

Vaquero, J.M., Gallego, M.C., Garcia, J.A., 2002, Geophys. Res. Lett. 29, 1997

Vaquero, J.M., 2007, Adv. Sp. Res. 40, 929

Vyssotsky, A.N., 1949, Meddelanden fran Lunds Astronomiska Observatorium Series II, Vol. 126, p.3-52

Wang, Y.M., 2008, Yi chi liang tian: Zhongguo gudai mushi chidu tianxiang jilu de lianghua yu guisuan, Shandong jiaoyu chubanshe

Whitelock, D. (Ed.), 1979, English historical documents, c. 500 1042, Oxford University Press

Wilkinson, E., 2000, Telling the time, in: Chinese history: A manual, 2nd ed., Cambridge, pp. 198-219

Willis, D.M., Armstrong, G.M., Ault, C.E., Stephenson, F.R., 2005, AnGeo 23, 945

Wittmann, A.D. \& Xu, Z.T., 1987, A\&AS 70, 83

Xu, Z., Pankenier, D.W., Jiang, Y., 2000, East Asian archaeoastronomy, Gordon and Breach

Yau, K. \& Stephenson, F., 1988, QJRAS 29, 175

Yau, K., Stephenson, F., Willis, D., 1995, A catalogue of auroral observations from China, Korea and Japan (193 BC - AD 1770), Technical report, Rutherford Appleton Lab

Zhou, D., Wang, C., Zhang, B., et al., 2014, Chinese Science Bulletin (DOI: 10.1007/S11434-014-0345-z)

Zolotova, N.V. \& Ponyavin, D.I., 2016, SoPh 291, 2869 